듬 SCHOOL of GRADUATE STUDIES

EAST TENNESSEE STATE UNIVERSITY
East Tennessee State University Digital Commons@ East Tennessee State University

\title{
Spirituality and Suicidal Behavior: The Mediating Role of Self-Forgiveness and Psychache
}

Benjamin B. Hall

East Tennessee State University

Follow this and additional works at: https://dc.etsu.edu/etd

Part of the Clinical Psychology Commons, Health Psychology Commons, Multicultural Psychology Commons, and the Social Psychology Commons

\section{Recommended Citation}

Hall, Benjamin B., "Spirituality and Suicidal Behavior: The Mediating Role of Self-Forgiveness and Psychache" (2017). Electronic Theses and Dissertations. Paper 3222. https://dc.etsu.edu/etd/3222

This Thesis - Open Access is brought to you for free and open access by the Student Works at Digital Commons @ East Tennessee State University. It has been accepted for inclusion in Electronic Theses and Dissertations by an authorized administrator of Digital Commons @ East Tennessee State

University. For more information, please contact digilib@etsu.edu. 
Spirituality and Suicidal Behavior: The Mediating Role of Self-Forgiveness and Psychache A thesis
presented to
the faculty of the Department of Psychology

East Tennessee State University

\begin{tabular}{c} 
In partial fulfillment \\
of the requirement for the degree \\
Master of Arts in Psychology \\
by \\
Benjamin Hall 2017 \\
\hline Jon R. Webb, Chair \\
Chris S. Dula \\
Stacey L. Williams
\end{tabular}

Keywords: Religion, Spirituality, Forgiveness, Psychache, Suicide 


\begin{abstract}
Spirituality and Suicidal Behavior: The Mediating Role of Self-Forgiveness and Psychache by

Benjamin Hall

Growing evidence for protective factors of spirituality against physical and mental health related outcomes has led to the consideration of spirituality as a protective factor for suicidal behaviors. Although initial support for this association is promising, spirituality has yet to be explored as it relates to psychache. Additionally, self-forgiveness has emerged as an important protective factor of suicidal behavior, but has not been explored in the context of psychache. Following a model developed by Webb, Hirsch, and Toussaint (2015), the current project explores the protective role of spirituality on suicidal behavior based on three dimensions of spirituality: ritualistic, theistic, and existential. A total of 262 individuals completed a self-report survey online through Amazon Mechanical Turk. Results indicate that only Existential Spirituality is related to suicidal behaviors. Further, self-forgiveness and psychache were found to be serial mediators of this relationship. Implications for clinical interventions and directions for future research are discussed.
\end{abstract}




\section{TABLE OF CONTENTS}

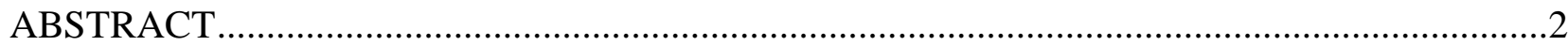

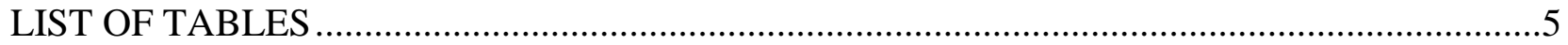

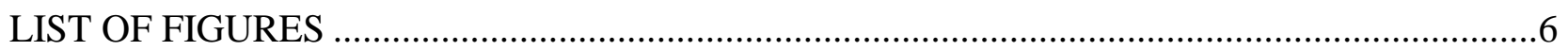

Chapter

\section{INTRODUCTION}

Spirituality 10

Conceptualizing Spirituality …................................................... 10

The RiTE Model ........................................................................12

Ritualistic Spirituality .............................................. 12

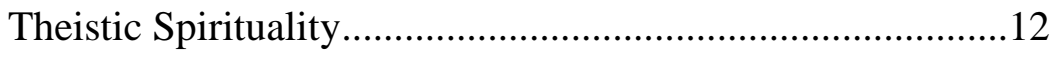

Existential Spirituality .............................................. 14

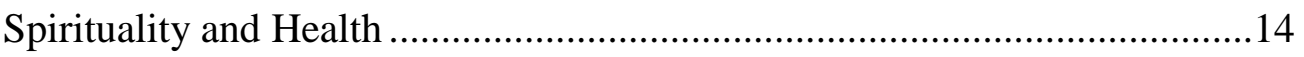

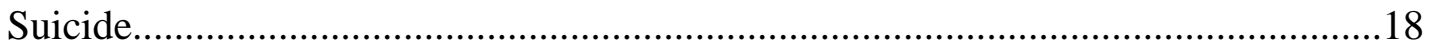

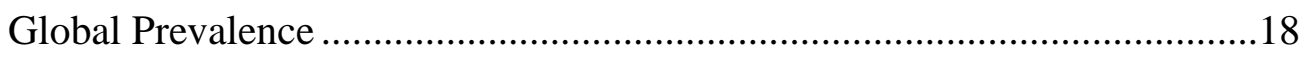

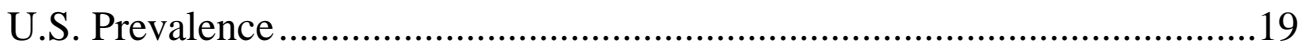

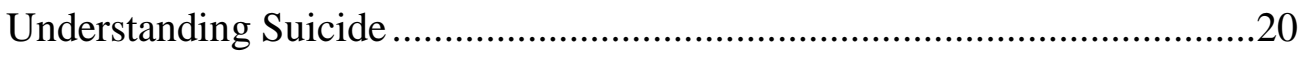

Biological factors of suicide .........................................21

Cultural factors of suicide................................................22

Sociological and interpersonal factors of suicide ................23

Intrapsychic factors of suicide .....................................23 
Psychache.

Empirical Evidence for Psychache .26

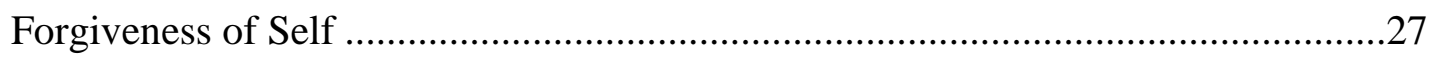

Conceptualizing Forgiveness of Self ................................................2

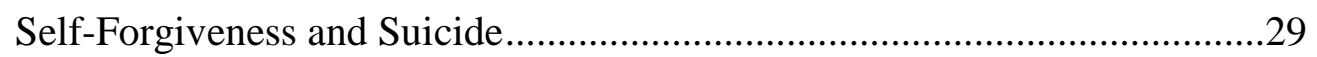

Self-Forgiveness and Spirituality ......................................................30

Self-Forgiveness, Spirituality, and Suicidal Behavior: A Theoretical

Model

Hypotheses

\section{METHOD}

Participants

Measures

Spirituality.

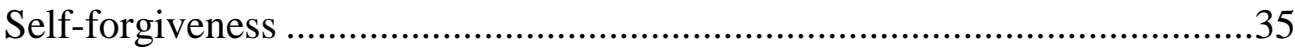

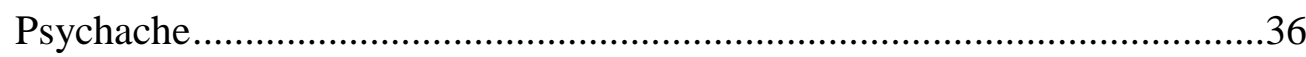

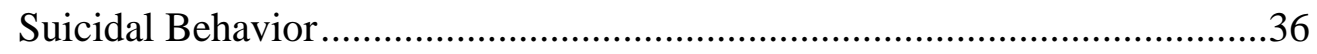

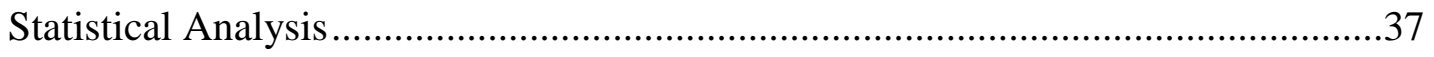

\section{RESULTS}

Sample Characteristics

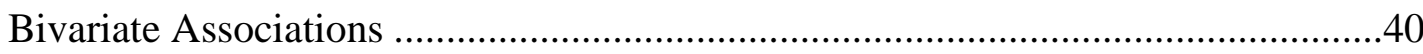

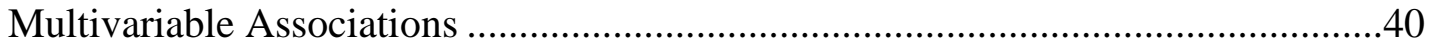


Review of Hypotheses

\section{DISCUSSION}

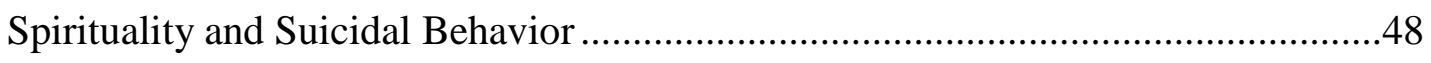

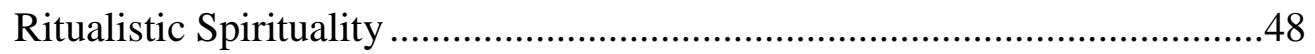

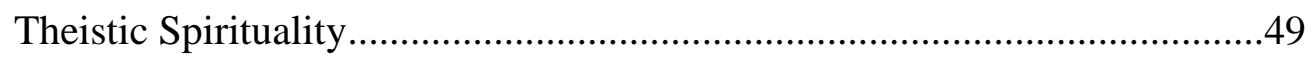

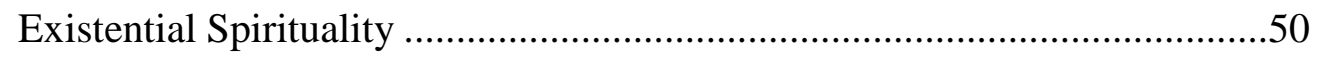

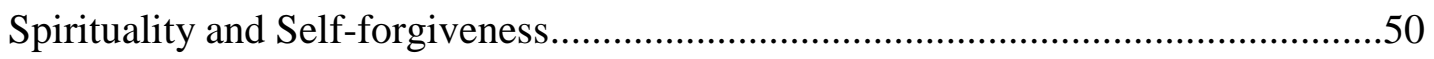

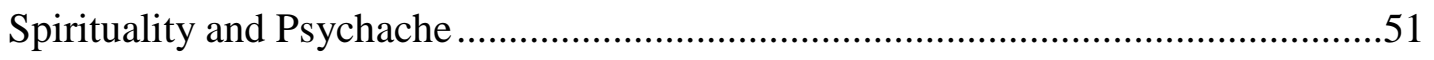

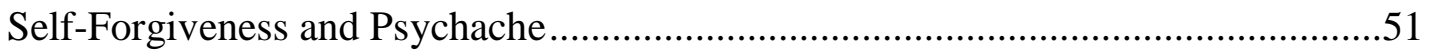

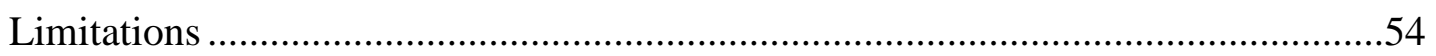

Conclusions and Future Directions ...............................................................57

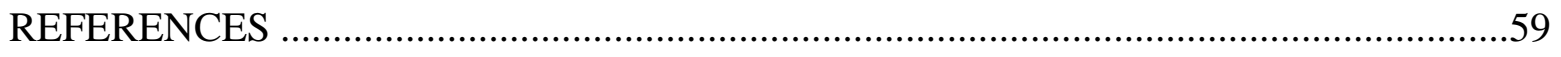

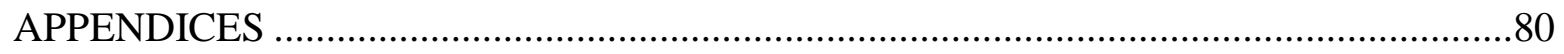

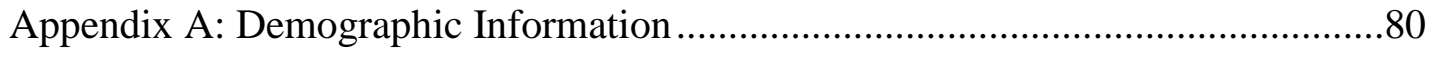

Appendix B: The RiTE Spirituality Measure .................................................83

Appendix C: The Heartland Forgiveness Measure ............................................. 87

Appendix D: Suicidal Behaviors Questionnaire- Revised...................................89

Appendix E: The Psychache Scale ........................................................... 91

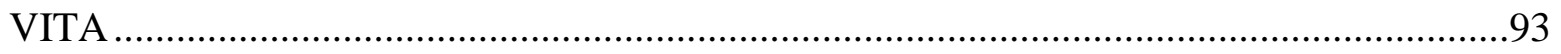




\section{LIST OF TABLES}

Table

Page

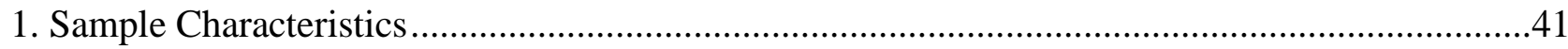

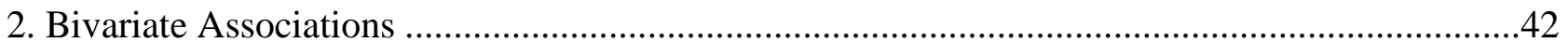

3. Multivariable Associations in the Context of Ritualistic Spirituality ......................................44

4. Multivariable Associations in the Context of Theistic Spirituality .........................................45

5. Multivariable Associations in the Context of Existential Spirituality ......................................46 


\section{LIST OF FIGURES}

Figure $\quad$ Page

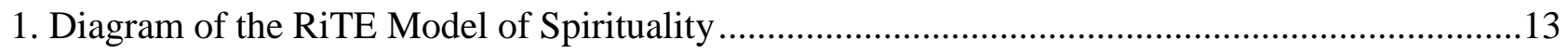

2. Theoretical Model of Forgiveness-Suicidal Behavior Association ..........................................33

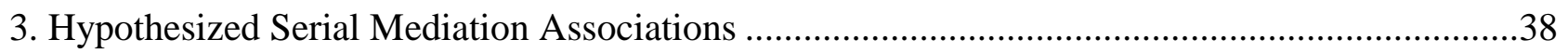




\section{CHAPTER 1}

\section{INTRODUCTION}

Religion and Spirituality have contributed to the shaping of virtually every society in the history of mankind, as a cultural construct that is deeply rooted in the belief systems of many individuals (see Cohen, 2009). Despite the secularization of American culture (Mouzelis, 2012), spirituality remains a relevant aspect of human behavior and cognition for $89 \%$ of Americans who report a belief in God or some universal spirit (Gallup, 2016). The importance of religion and spirituality is not only evident in terms of its cultural prominence throughout history and in modern society, but also in terms of its impact on individuals' lives. In particular, the influence of religion and spirituality on health has gained increasing attention in recent decades, providing empirical support for the positive association between religion and spirituality and better physical and mental health related outcomes (Horton, 2015; see also Koenig, King, \& Carson, 2012). Related to mental health outcomes, researchers have more recently taken a deeper look at the relationship between spirituality and suicide (Caribe et al., 2015; Kopacz, 2015; Lester, 2012).

Rates of suicide have steadily increased in the last decade (Xu, Kochanek, Murphy, \& Arias, 2014) placing suicide as the $10^{\text {th }}$ leading cause of death in the United States (Curtin, Warner, Hedegaard, 2016a). As such, efforts to better understand the risk factors and precipitants in an attempt to develop more effective methods of prevention and intervention are warranted. Recent evidence suggests that spirituality may provide a protective quality against suicide (Bryan, Graham, \& Roberge, 2015; Kopacz, 2015); however, there is some debate as to whether or not this buffer is inherent in spirituality or if other variables contribute to this effect that are illuminated by spiritual orientations but are not exclusive to spirituality (Currier, Kuhlman, \& 
Smith, 2015). One such variable that falls within this description is self-forgiveness. While the pool of literature supporting a relationship between self-forgiveness and suicide (Bryan, Theriault, \& Bryan 2015; Hirsch, Webb, \& Jeglic, 2012) is growing, the relationship between self-forgiveness, suicide, and spirituality has yet to be fully explored.

Religion and spirituality's relationship to suicide has largely been explored through its protective role against risk factors for suicide such as depression (Cole-Lewis, Gipson, Opperman, Arango, \& King, 2016). Less attention has been devoted to other proposed precipitants of suicide such as the theory of psychache (Schneidman, 1993), which has gained increasing attention in recent years (Berlim et al., 2003; Holden, Mehta, Cunningham, and McLeoud 2001; Troister, Agata, \& Holden, 2015). While research on psychache is still in its infancy, existing literature lends support for the notion that the theory of psychache capitalizes on unique precipitants of suicidal behaviors that are not accounted for by depression or hopelessness (DeLisle \& Holden, 2009; Troister, Agata, \& Holden, 2015). Psychache has yet to be explored as it relates to spirituality. Understanding psychache in the context of spirituality may further our efforts to develop more effective methods for clinical intervention and prevention.

To contribute to the existing literature and to help abridge the gaps in our knowledge of spirituality and suicide, the current project proposes to further explore the relationship between spirituality and suicide with a particular interest in the role of self-forgiveness and psychache. Specifically, self-forgiveness and psychache are proposed to be mediators of the relationship between spirituality and suicide. This proposed association between spirituality, self-forgiveness, psychache, and suicidal behaviors can be understood in the context of a theoretical model proposed by Webb, Hirsch, and Toussaint (2015). According to this model, forgiveness, as a 
component of spirituality, is directly and inversely related to suicidal behavior while also indirectly reducing suicidal behavior through mechanisms of health related functioning and psychological distress. This model serves as a theoretical foundation for the current project and will be explored more fully as it relates to the associations previously proposed.

\section{Spirituality}

\section{Conceptualizing Spirituality}

The scientific study of religion and spirituality has long been divided by conceptual and theoretical disagreements on the definition and measurement of such constructs. The lack of consensus within this subfield of psychology has led to no less than thirty-five distinct measures of religion or spirituality (Hill \& Hood, 1999; Monod et al., 2011). Among these competing conceptualizations exists the view that the scientific study of spirituality is all around inappropriate within academic institutions (Gray, 2006). Despite the criticism associated with spirituality in the scientific literature, religion and spirituality remain core aspects of the human condition with $72 \%$ of Americans reporting religion to be at least fairly important to them (Gallup, 2015).

Beyond the importance of religion and spirituality to individual belief systems, religion and spirituality have been shown to play an important role in both physical and mental health related outcomes. While research supporting the relationship between religion, spirituality, and health offers a valid rebuttal to the argument that religion and spirituality have no place in the scientific literature, it does little to clarify a ubiquitous conceptualization of religion and spirituality or to distinguish those aspects of religious and spiritual involvement that relate to other variables. Therefore, a more universal conceptual and theoretical framework for understanding religion and spirituality should be a priority for furthering this area of scientific 
study. Previous attempts to categorize common conceptualizations of spirituality have yielded a number of religious/spiritual categories: general spirituality, spiritual well-being, spiritual coping, spiritual needs (Monod et al., 2011); organized religion versus personal spirituality, substantive religion versus functional spirituality, and negative religiousness versus positive spirituality (Zinnbauer, Pargament, \& Scott, 1999); and intrinsic versus extrinsic spirituality (Slater, Hall, \& Edwards, 2001; see also Allport \& Ross, 1967). The polarization of competing views on spirituality likely stems from personal biases, which impede the ability to objectively define and engage in the scientific study of spirituality (Zinnbauer et al., 1999). Thus, a comprehensive, scientific conceptualization of spirituality should not arise from personal attempts to prove the principles of any given spiritual worldview.

One challenge to conceptualizing this particular area of study is the need to distinguish between religion and spirituality. Existing conceptualizations of these constructs often capitalize on religious involvement or importance (Altemeyer \& Hunsberger, 2004; Connors, Tonigan, \& Miller, 1996; Huber \& Huber, 2012), characteristics of a traditional spiritual worldview (de Jager Meezenbroek et al., 2012), or a mixture of the two without adequately distinguishing one from the other (Underwood \& Teresi, 2002). Thus, few models of spirituality have been proposed that adequately express the breadth and quality of human spirituality. A relatively recent push for a broader, more pluralistic conceptual framework of spirituality (Zinnbauer et al., 1999) has bred several attempts to more adequately capture the nature of human spirituality. The RiTE model of spirituality (Webb, Toussaint, \& Dula, 2014) is one such attempt that offers a view of spirituality as a multidimensional and universal human experience (see Pargament, 1999, 2013; Pargament, Mahoney, Exline, Jones, \& Shafranske, 2013; Piedmont, 1999; Piedmont \& Wilkins, 2013). 
The RiTE model. The RiTE model of spirituality proposes a view of spirituality defined as "the salient, searching pursuit of the transcendently sacred ritualistic, theistic, and/or existential aspects of the human condition" (Webb et al., 2014, p. 974). This definition expresses the underlying foundation of the RiTE model as a tri-dimensional model of spirituality comprised of ritualistic, theistic, and existential domains of spirituality. This conceptualization of spirituality diverges from more traditional views in its emphasis on diverse spiritual worldviews (Webb et al., 2014) and its elimination of the commonly perceived "religiousness versus spirituality dichotomy..." (p. 975). Thus, it is important to consider that spirituality within the RiTE model provides an overarching term that envelopes the concept of religion. A visual representation taken from Webb et al. (2014) can be seen in Figure 1. Each dimension of spirituality within the RiTE model is thought to be related while still acknowledging the critical, and often subtle, differences within spirituality. Further explanation of these dimensions will demonstrate their unique contribution to this comprehensive conceptualization of spirituality.

Ritualistic spirituality. Ritualistic Spirituality encompasses the elements most closely associated with organized religion such that it entails a "structured, ritualistic connection with deity" (Webb et al., 2014, p. 973). This dimension incorporates the socially and culturally recognized features of a formal belief system apart from, yet related to, personal spirituality. As the name suggests, this dimension emphasizes the rituals and behavioral components of spirituality such as involvement in organized forms of worship or adherence to a set of rules outlined in a formal belief system.

Theistic spirituality. The inclusion of the dimension of theistic spirituality allows for a personal "non-structured connection with deity, including little to no affiliation with organized religion" (Webb et al., 2014, p. 973). Theistic spirituality is an individualized form of spirituality 


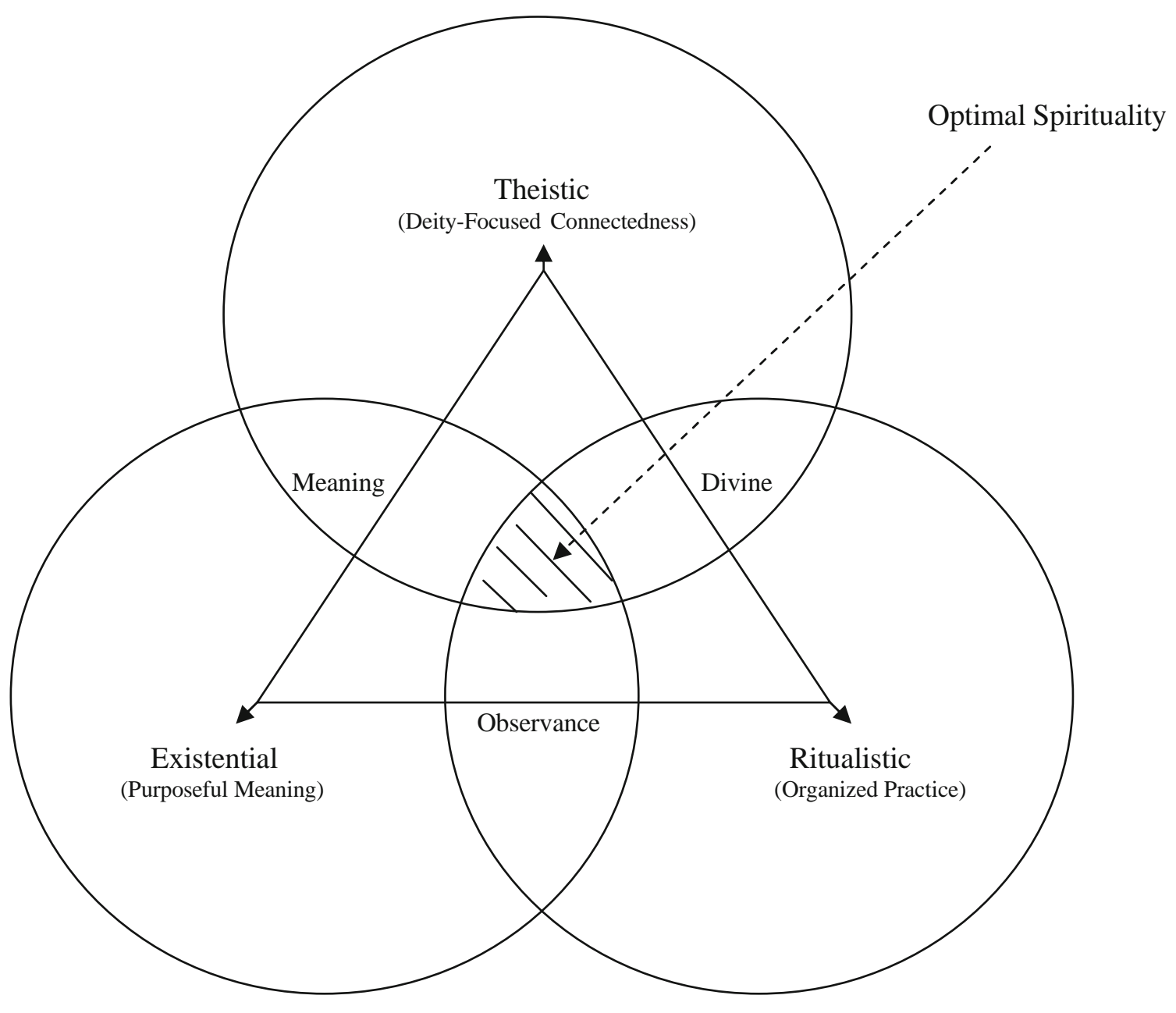

Figure 1.

Diagram of the RiTE Model of Spirituality (Webb et al., 2014). Adapted from Webb (2007/2003).

Source Webb et al., 2014 
that shares a common goal with ritualistic spirituality in its pursuit of a divine connection (Webb, 2007). This commonality between ritualistic and theistic spirituality is important in understanding spirituality as an overarching term that envelopes both theistic and ritualistic aspects of spirituality without necessarily separating religion from spirituality.

Existential spirituality. Existential Spirituality contributes to the breadth of the RiTE model through its inclusion of aspects of spirituality that are independent of the belief in deity/deities. It is in this regard that the RiTE model diverges from many other conceptualizations of spirituality. Webb et al. (2014) describe existential spirituality as a "nontheistic search for meaning and purpose" (p. 973). It is this dimension of spirituality that allows the RiTE model to allow for the "explicit exclusion of the notion of deity, thereby allowing the construct of spirituality to be more inclusive of diverse worldviews regarding explaining and understanding the transcendent nature of the human condition" (Webb et al., 2014, p. 973).

Adopting this model permits a broader exploration of human spirituality as a universal experience that incorporates a wide variety of spiritual orientations. Thus, the relationship between spirituality and health related outcomes, including suicide, becomes more salient as a relevant area of study by expanding the range of individuals to whom its benefits may apply. Further, this broad conceptualization of spirituality can provide important implications for clinical intervention.

\section{Spirituality and Health}

The relationship between spirituality and health has been primarily studied in the context of religious or spiritual practices such as prayer (Linardakis et al., 2015; Paiva, Paiva, Yennuraljalingam, \& Hui, 2014; Upchurch, Dye, Chyu, Gold, \& Greendale, 2010), church attendance (Chiswick \& Mirtcheva, 2013; Koenig \& Vaillant, 2009), and meditation (Galante, 
Galante, Bekkers, \& Gallacher, 2014; Lomas, Ridge, Cartwright, \& Edginton, 2014). The association between these and other spiritual practices and health related outcomes is thought to depend on sociological principles that promote health behaviors and indirectly link spirituality to better health (Ellison \& Levin, 1998; McCullough \& Smith, 2003). George, Larson, Koenig, and McCullough (2000) outline the mechanisms that are theorized to play a role in the relationship between spirituality and health. First, many religions discourage engaging in certain risk behaviors that may negatively affect health such as substance use, sexual promiscuity, and violence. Second, religious involvement is theorized to increase social support, which has been linked to better health related outcomes (Milner, Krnjacki, Butterworth, \& LaMontagne, 2016; Uchino, 2006). The third and final mechanism outlined by George et al. is the Coherence Hypothesis. The Coherence Hypothesis suggests that spirituality provides a source of existential meaning from which individuals derive purpose and hope in suffering. This source of meaning is thought to minimize the health impact of adverse life events. In the context of Webb et al's. (2015) previously mentioned theoretical model, spirituality is thought to promote positive psychological traits (e.g., forgiveness) in such a way that reduces negative health related outcomes such as substance abuse and suicide. Additionally, spirituality may serve as a resource for adaptive coping with stress and other negative health influences associated with illness (Ai et al., 2010). Although empirical evidence has supported a positive relationship between spirituality and physical health outcomes (Masters \& Hooker, 2013; Paiva, Paiva, Yennurajalingam, \& Hui, 2014; Park et al., 2016; Powell, Shahabi, \& Thoresen 2003; Roff et al., 2005), the positive association between spirituality and mental health may be more robust (Koenig \& Larson, 2001). 
The relationship between spirituality and mental health has received more consistent empirical support than that of physical health. This effect has been shown across a variety of mental health related issues including depression (Miller et al., 2012; Blazer, 2012; Lester, 2012; Berry \& York, 2011), anxiety (Piacentine, 2013; Johnson et al., 2011), and suicidal ideation (Lester, 2012; Caribe et al., 2015).

As a significant predictor of suicidal behaviors (Britton et al., 2015), spirituality's association with depression is an important factor in understanding spirituality as a buffer against suicide. General religious belief has been shown to be associated with lower levels of depression. Murphy et al. (2000) gathered data from 271 individuals diagnosed with major depression to assess the role of religious belief in this clinical diagnosis. Religious belief significantly predicted lower levels of depression. This study suggests that religious belief may be more relevant to those already experiencing depression rather than as a protective factor against the onset of depression. Austin and Lennings (1993) reported similar results from their study of 57 participants who reported bereavement in the 5 years prior to the study. Those indicating a belief in God were more likely to have lower levels of depression. Miller et al. (2012) explored the longitudinal effects of religiousness on major depression in a sample of individuals at both high and low risk levels for depression. Participants who identified religion/spirituality as having high personal importance were less likely to experience a major depressive episode in the 10 years following. Further, this effect was more prominent among participants labeled as high-risk defined as having a parent with depression. The protective factor of spirituality was stronger for recurring episodes of depression rather than the onset of depressive symptoms.

Attendance at religious services has also been extensively studied as it relates to depression. While there are some discrepancies in the literature, research generally supports the 
relationship between church attendance and better mental health. Balbuena et al. (2013) report decreased symptoms of depression among individuals who attend religious services at least monthly. This relationship between church attendance and depression has been widely reported (Wright, Frost, \& Wisecarver, 1993; Norton et al., 2008). Gender differences may also exist in this relationship with females being more likely to receive the protective benefits of religious attendance against depression (Rasic, Kisely, \& Langille, 2011). Despite these findings, others have failed to support the relationship between religious service attendance and depression (Miller et al., 2013; Murphy et al., 2000). Murphy et al. suggest that this could be because people may turn to religious activities to cope with depression. Thus, the rate of depression among church-attendees may be higher than expected.

As previously mentioned, spirituality has been theorized to protect against health risk behaviors such as substance use (George et al., 2000), which places individuals at a greater risk for suicide (Pompili, 2012). Further, the risk of suicide among individuals with depression may be greater among those with a co-occurring substance abuse problem (Effinger \& Stewart, 2012). Empirical support for this theory has been well documented. Rasic, Kisely, and Langille suggest that church attendance is a protective factor against both suicidal ideation as well as substance abuse (see also Kleiman \& Liu, 2014). Alcohol use and dependence rates have been shown to be lower among individuals who frequently attend religious services (Koenig \& Vaillant, 2009), which likely contributes to an indirect relationship between overall physical health as well as suicidal ideation.

Spirituality may also directly reduce suicidal behaviors by condemning the act of suicide. Seigrist (1996) demonstrated a reduction of suicidal ideation among individuals who attend regular religious services and suggests that religion protects against suicidal behaviors through 
promoting the view that suicide is tied to morality. A view of suicide as immoral may buffer the effects of depression, substance abuse, and other factors that contribute to suicidal behavior.

Evidence suggests that prayer may also be a factor in promoting mental health. Boelens, Reeves, Replogle, and Koenig (2012) found prayer to reduce the level of anxiety and depression in women undergoing prayer intervention. Furthermore, prayer did not only result in a reduction of depression and anxiety, but also an increase in optimism. The relationship between prayer and mental health may be more salient for those at a greater risk of experiencing poor mental health, such as open-heart surgery patients (Ai et al., 2010). Prayer may be considered a form of meditation, which helps explain its relationship with mental health, as meditation has recently emerged as a tool used in clinical intervention for a variety of health issues. Sorrell (2015) provides an overview of this research demonstrating the clinical utility of meditation for issues such as anxiety, depression, chronic pain, and loneliness.

While the religious and spiritual practices listed here contribute to our understanding of the relationship between spirituality and mental health, they may reflect only a small portion of the influential factors of spirituality on mental health and may heavily emphasize a ritualistic understanding of spirituality. This neglects other aspects of spirituality that may be more characteristic of theistic and existential spirituality in regards to the RiTE model. Further exploring these domains of spirituality as they relate to other variables will help broaden our knowledge of the relationship between spirituality and mental health, specifically suicide.

\section{Suicide}

\section{Global Prevalence}

The well-warranted attention devoted to suicide in recent years has furthered our understanding of the epidemiology of suicide. Suicide is a global phenomenon resulting in over 
800,000 deaths each year, a small percentage of the number of individuals who attempt suicide (World Health Organization [WHO], 2014). Moreover, the World Health Organization suggests that the number of completed suicides is likely underestimated due to the sensitivity and legal ramifications of suicide in some nations. Nonetheless, this conservative estimate places suicide as the fifteenth leading cause of death worldwide. Half of all violent deaths in men and nearly three-fourths in women are attributable to suicide (WHO, 2014).

Worldwide, men have accounted for more deaths by suicide than women (WHO, 2014). The extent of this discrepancy varies across nations with higher income countries observing greater gender disparities at a 3.5 to 1 male to female ratio (WHO, 2014). Lower income countries observe lower male to female ratios at 1.6 to 1 , respectively. The role of a nation's economic stability in the gender disparity related to suicide is unclear but may contribute to the accessibility of more lethal methods of suicide more commonly used by men.

When categorized by age, global suicide rates tend to follow a pattern with the highest number of suicides occurring in individuals over the age of 70 ; however, after accounting for this age group, there is some variability in suicide rates by age cross-nationally (WHO, 2014). The lowest at-risk group is those under the age of 15 , for whom rates of suicide are more than ten times lower than those aged 15 to 24 (Curtin, Warner, \& Hedegaard, 2016b).

\section{U.S. Prevalence}

Although suicide is a universal occurrence, the United States experiences slightly elevated rates of suicide at 13 per 100,000 population, two more per 100,000 than the global average (Curtin et al., 2016a; WHO, 2014). Males are more than three times as likely to die by suicide than females in the U.S., though this gender gap has decreased over the past fifteen years suggesting that increases in female deaths by suicide are growing at a more rapid rate than that of 
males (Curtin et al., 2016a). Gender disparities are proposed to exist due to differences in the fatality of methods used by men and women (WHO, 2014). The most common method of suicide for males is firearms while women are more likely to use poison (Curtin et al., 2016a; WHO, 2014). Although men are more likely to die by suicide, women are at a greater risk for non-fatal attempts and expressing suicidal ideation (Substance Abuse And Mental Health Services Administration [SAMHSA], 2013).

Following global trends, the age group for which suicide is most prevalent in the U.S. is the elderly, particularly those 85 and older (CDC, 2013). Middle age individuals represent the next highest age group followed by adolescents and young adults.

In 2013, more than 494,000 individuals were treated for self-induced injuries in the U.S. resulting in an estimated $\$ 44.6$ billion economic burden (CDC, 2015). This economic burden has the potential to increase given that 9.3 million Americans have seriously considered suicide within the past year and 2.7 million individuals have made a plan to die by suicide (SAMHSA, 2013). This economic burden fails to compare to the psychological weight carried by the relatives and friends of suicide victims (Saarinen, Viinamäki, Hintikka, Lehtonen, \& Lönnqvist, 1999). A better understanding of suicide is a vital step in developing preventative measures for this preventable mental health outcome.

\section{Understanding Suicide}

While suicide may be a universally understood term that accurately conveys an outcome, understanding suicide also entails the precipitant factors leading up to this outcome. However, a tendency to summarily equate the outcome with otherwise general precipitants may impair our ability to accurately understand the act of suicide. That is to say that the factors leading to the act of suicide are highly variable. Shneidman (1993) highlights this variability in his description of 
suicide as a "multifaceted event [in which] biological, socio-cultural, sociological, interpersonal, intrapsychic, logical, conscious and unconscious, and philosophical elements are present, in various degrees, in each suicidal event" (p. 4). As such, Shneidman suggests that no individual suicidal event can be understood from the sole contributions of a single discipline.

Biological factors of suicide. Although a full review of the biological etiology of suicide is beyond the scope of this paper, a brief review of the literature on biological factors of suicide is important for laying a foundation for a multifaceted conceptualization of suicide. Biological rhythms, "any cyclic change in a bodily chemical or function" (Hedge, 2013, p.1), are one physiological component thought to be related to suicide. Diurnal variation is one form of biological rhythm that has been shown to be associated to an increased risk for suicide among individuals with Seasonal Affective disorder (Bahk, Han, \& Lee, 2014). Specifically, individuals who prefer an advanced sleep period, or are most active in the morning experience a lower risk for suicide. A heightened risk for suicide has also been indicated in samples of individuals diagnosed with PTSD and Bipolar disorder experiencing circadian rhythm dysregulation (Dell'Osso et al., 2014; Pawlak et al., 2015). The association between biological rhythmicity and suicide may offer one explanation to the commonly reported association between suicide and seasonality (Christodoulou et al., 2012).

A more common approach to understanding the biology of suicide highlights the role of various neurotransmitters including serotonin (Miller et al., 2013; Turecki, 2014; Pandey, 2013), norepinephrine (Kim et al., 2014; Jokinen, Ouda, \& Nordstrom, 2010), and dopamine (Suda et al., 2009; Turecki, 2014). More specifically, reduced serotonin transporter receptor binding and polymorphisms of the norepinephrine transporter gene have been linked to suicide risk (Miller et al., 2013; Kim et al., 2014). Lithium's role in reducing suicide risk among mood disorder 
patients points to the role of dopamine as lithium modulates dopaminergic factors (Turecki, 2014). Some evidence identifies cellular alterations and genetic markers in the brains of suicide victims as mechanisms by which neurochemical imbalances contribute to suicide (Mann, 1998). Although the direct role of these chemicals in suicide is not entirely clear, the evidence for a biological basis of suicide is indisputable. The organic features of suicide play an important role in our understanding of suicide, though these factors only explain a portion of the variance in suicides.

Cultural factors of suicide. Although suicide is observed universally, it may be best understood as a cultural event (Shneidman, 1993). Public opinions of suicide differ drastically across cultures (Stack \& Kposowa, 2015). Suicide in some cultures, such as Japanese culture, has even been perceived as an honorable act (Flaskerud, 2014; Young, 2002). It has been suggested that, contrary to Western culture's moral condemnation of suicide, Eastern religious values may play a role in promoting a more positive view of suicide (Picone, 2012; Young, 2002). Eastern religions may be more heavily rooted in ancient philosophies that promote any form of selfsacrifice as morally acceptable (Young, 2002). Even within Western culture's condemning views of suicide, some level of dignity is associated with the ability to control one's own state of existence. This is reflected in the instatement of Death with Dignity laws in four U.S. states that permit physician-assisted suicide for terminally ill patients (i.e., California [End of Life Option Act, 2016], Oregon [Death with Dignity Act, 1997], Vermont [Patient Choice and Control at the End of Life Act, 2013], and Washington [Washington Death with Dignity Act, 2008]). Given the variation in cultural perceptions of suicide, further explanation of the, seemingly, self-defined act of suicide as it is viewed in Western society is warranted. In Western culture, suicide may be defined as "a conscious act of self-induced annihilation, best understood as a multidimensional 
malaise in a needful individual who defines an issue for which the suicide is perceived as the best possible solution" (Shneideman, 1993, p. 4; Shneidman, 1985, p. 186).

Sociological and interpersonal factors of suicide. Emile Durkheim was among the first to present a sociological approach to suicide, and his work has been exceedingly influential in more current perspectives of suicide (Scourfield, Fincham, Langer, \& Shiner, 2012). Building on the work of Durkheim, many contemporary theories of suicide emphasize social integration as a critical factor of suicide (Wray, Colen, \& Pescosolido, 2011; Zhang, 2016). The social integration theory of suicide suggests that one's level of social connectedness influences their likelihood for suicide (Zhang, 2016). Empirical support for this theory is well documented (see Stack, 2000). A similar and more recent perspective of suicide, the Interpersonal Theory of Suicide (Joiner, 2005), also emphasizes the sociological components of suicide. This theory posits that thwarted belongingness, perceived burdensomeness, and acquired capability are the root cause of suicide (Joiner, 2005; Zhang, 2016). While both of these theories (i.e., the social integration theory and the Interpersonal Theory) contribute to a multifaceted understanding of suicide, neither is sufficient in explaining the cause of suicide (Zhang, 2016).

Intrapsychic factors of suicide. Suicide is commonly attributed to intrapsychic issues related to mental illness (Lester \& Bean, 1992). Indeed, individuals diagnosed with some form of psychopathology are at a greater risk for suicide than the general population (Chen \& Dilsaver, 1996; Harris \& Barraclough, 1997). In a thorough investigation of the relationship between mental illness and suicide, Harris and Barraclough (1997) found that at least 36 out of 44 mental disorders studied significantly increased an individual's risk of suicide. Mental disorders that represented the highest risk of suicide include Bipolar, Major Depression, and Anorexia Nervosa. One proposed explanation for why psychopathology increases the risk for suicide is 
related to the commonality of impulsivity across mental illnesses combined with a lowered threshold for psychological distress (Mann, 1998). Although evidence relating suicide to mental illness is strong, mental illness cannot be entirely accountable for suicide (Hendin, 1991); that is, the presence of suicidal behavior does not, of necessity, imply mental illness.

The logic and philosophy of suicide. Because of the well-known relationship between suicide and mental illness, there is a tendency to describe suicide as the outcome of an underlying pathology (Zhang, 2016), such that suicide is to mental illness what a heart attack is to hypertension. While these analogies hold true to an extent, they also confirm the view of suicide as an inevitable outcome of a terminal disease. Rather than being described as the outcome of illness, suicide may be better understood as a rational solution to a perceived problem (Shneidman, 1993). Understanding suicide as a solution highlights an adaptive, albeit maladaptive, function of suicide that serves to fulfill a particular psychological need of the victim. Shneidman (1993) argues from this perspective that "there are no needless suicides" (p. 3). This perspective of suicide illuminates the logical reasoning that leads an individual to consider, attempt, and die by suicide.

The view of suicide as a solution indicates suicide as a philosophical problem (Mathews, 1998), highlighting its existential nature. To consider suicide is to implicitly question the value and meaning of life. Mathews (1998) describes the existential philosophy that nothing meaningful comes from outside us. From this point of view, suicide may be seen as the result of a persistent lack of existential meaning. This may illuminate one mechanism of spirituality's protective role against suicide. Spirituality and religion may serve as a solution to the philosophical and existential struggles that drive a motivation for suicide. 
Conscious and unconscious factors of suicide. The unconscious motivations for suicide have been less explored than the more evident conscious factors, some of which have been previously mentioned. Nonetheless, evidence is building for the role of unconscious processes in suicide. In a psychodynamic approach to suicide, Fowler, Hilsenroth, and Piers (2001) found a high risk for suicide among participants who displayed "overwhelming feelings of self-hatred and perceptions of the self as damaged, when combined with vulnerability to ego boundary disturbance" (p. 177). Hendin (1991) suggests that suicide is motivated by unconscious processes such as rage, guilt, hopelessness, despair, and desperation to fulfill an unconscious desire such as revenge, self-punishment, or atonement. Although it is difficult to definitively determine the extent to which unconscious processes influence suicide in any given case, the empirical and theoretical literature supports the plausible role of such processes in suicide (Fowler, Hilsenroth, \& Piers, 2001; Hendin, 1991; Roalfe, 1928).

Although the aforementioned factors (i.e., biological, cultural, etc.) are present in each suicide in varying degrees, Shneidman $(1993,1996)$ asserts that above all of these elements, suicide is psychological. That is, suicide occurs as the result of intense psychological pain, or psychache, and all of these other elements are relevant, but only inasmuch as they contribute to psychache (Shneidman, 1993). According to Shneidman (1993), when suicide risk is present, the task is to "mollify the psychache ... no psychache, no suicide" (pp. 53 \& 56).

\section{Psychache}

Shneidman (1993) describes psychache as a deeply rooted "hurt, anguish, soreness, aching, psychological pain in the psyche, the mind" (p. 51). Further, this psychological pain is the central cause of suicide (Shneidman, 1996). Psychache results when psychological needs are unfulfilled. Suicide results when death is preferable to living with these unmet psychological 
needs. Not every instance of psychache results in suicide. Rather, suicide occurs as a response to a lowered threshold for tolerating psychological pain such that "in the mind of the chief protagonist suicide is a solution- the solution- to a perceived problem, dilemma, challenge, difficulty, seemingly inescapable or intolerable situation" (Shneidman, 1993, p. 16) Although closely related, psychache diverges from depression in its existential nature. Depression has biochemical and physiological roots and is related to suicide only to the extent that it is related to psychache (Shneidman, 1993). Depression, as Shneidman (1993) states, "is not a legitimate cause of death" (p. 55). Psychache is necessarily present in virtually every suicide while depression is not (Shneidman, 1993).

\section{Empirical Evidence for Psychache}

The early stages of research have yielded support for Shneidman's theory of psychache as suicide. Holden et al. (2001) were among the first to provide empirical support for the theory of psychache through the construction of a valid measurement instrument. The initial psychometric properties of the Psychache Scale (Holden et al., 2001; Troister \& Holden, 2013) distinguished psychache from other factors of suicide such as depression and hopelessness. Since the development of the psychache scale, growing evidence has supported the predictive validity of psychache for suicide (Berlim et al., 2003; DeLisle \& Holden, 2009; Troister \& Holden, 2010). In a sample of 60 psychiatric outpatients, Berlim et al. (2003) found psychache to be a significant predictor of suicidality, even after controlling for depression and hopelessness.

DeLisle and Holden (2009) further confirmed the distinguished relationship between psychache and suicidality in a large, cross-sectional sample of college undergraduates. Psychache does not only contribute unique variance to the prediction of suicide, but also has been found to be a stronger predictor of suicide than depression and hopelessness (Troister \& Holden, 2010). 
Psychache has also been studied using a longitudinal design to assess the ability of psychache to predict changes in suicidal ideation (Troister, Davis, Lowndes, \& Holden, 2013; Troister \& Holden, 2012). Troister and Holden (2012) found changes in psychache to be associated with changes in suicidal ideation over a two-year period. Further, psychache was the only unique contributor to predicting change in suicidal ideation compared to depression and hopelessness. These results were replicated in a large sample of high-risk undergraduate students over a five-month interval (Troister et al., 2013).

Although preliminary evidence provides strong support for the construct and predictive validity of psychache, the association between psychache and suicide is in need of further empirical investigation. Further, the exploration of protective factors against psychache has been neglected. The coherence hypothesis previously discussed (George et al., 2000) may indicate spirituality as a protective factor against psychache. As a source of existential meaning, spirituality may combat the philosophical and existentially driven psychological distress implicated in psychache. Similarly, the model proposed by Webb et al. (2015) may indicate selfforgiveness as a mechanism whereby spirituality reduces psychache. The current project aims to address this neglect by exploring spirituality as a protective factor against psychache and, in turn, suicidal ideation. More specifically, self-forgiveness is evaluated as a characteristic of spirituality that aids in the protective role of spirituality against psychache and suicidal ideation.

\section{Forgiveness of Self}

\section{Conceptualizing Self-Forgiveness}

Forgiveness is often conceptualized as a unified construct, such that one dimension of forgiveness (e.g. forgiveness of self) is thought to be sufficiently similar to other dimensions of forgiveness (e.g. forgiveness of others) in their definition and capacity to influence other 
variables. However, research has shown that dimensions of forgiveness can have autonomous associations with diverse variables (Maltby, Macaskill, \& Day, 2001). Ross, Hertenstein, and Wrobel (2007) supported a two-component model of forgiveness by demonstrating the discriminant properties of self-forgiveness and other-forgiveness. Thus, adequate consideration is often not given to the independent characteristics of varying dimensions of forgiveness. Although multiple dimensions of forgiveness (i.e. forgiveness of self, forgiveness of others, forgiveness of God, etc.) have been linked to a variety of positive health related outcomes (see Toussaint, Worthington, \& Williams, 2015), forgiveness of self has emerged as possibly the most influential dimension of forgiveness (Webb \& Jeter, 2015; see also Woodyatt, Worthington, Wenzel, \& Griffin, 2016). Despite its relative importance, forgiveness of self has received a limited amount of attention compared to other dimensions of forgiveness in recent decades (Hall \& Fincham, 2005).

In a comprehensive review of the literature on self-forgiveness, Webb, Bumgarner, Conway-Williams, and Dangel (2016) identified five core themes among varying definitions of self-forgiveness: reconciliation, acceptance, accountability for wrong-doing, connection with the human community, and a genuine effort to change in the future. Further, Webb et al. (2016) propose a definition of self-forgiveness as a phenomenon that:

occurs over time and is a deliberate, volitional process initiated in response to one's own negative feelings in the context of a personally acknowledged self-instigated wrong, that results in ready accountability for said wrong and a fundamental, constructive shift in one's relationship to, reconciliation with, and acceptance of the self through humanconnectedness and commitment to change (p. 10). 
As the study of self-forgiveness moves toward a ubiquitous understanding, there is agreement that self-forgiveness is not synonymous with forgetting or pardoning a transgression (Tangney, Boone, Dearing, 2005).

Drawing from the implications of the work of Beck (1962) and Ellis (1962), who describe the human tendency to more critically evaluate the self than others, Macaskill (2012) describes the realization of self-forgiveness as more difficult to achieve and, potentially, more influential to health than other levels of forgiveness. Webb et al. (2006) demonstrated a similar hierarchical structure among levels of forgiveness with forgiveness of self being more difficult to achieve than forgiveness of others and feeling forgiven by God. Considering this difficulty, selfforgiveness may be a particularly relevant issue to address for clinical intervention and, more specifically, suicidal individuals.

\section{Self-Forgiveness and Suicide}

Among the limited number of studies that have examined the relationship between forgiveness and suicide, self-forgiveness has emerged as a potential buffer against suicidal behaviors (Bryan et al., 2014; Chang, Kahle, Yu, \& Hirsch, 2014; Nagra, Lin, \& Upthegrove, 2016). Nagra et al. (2016) found self-forgiveness to be inversely related to suicide attempts in 323 individuals who reported self-injurious behaviors. Self-forgiveness has also been shown to protect against suicide in victims of domestic abuse (Chang et al., 2014), depressed individuals (Hirsch, Webb, \& Jeglic, 2011; Nsamenang, Webb, Cukrowicz, \& Hirsch, 2013), and veterans with Post-Traumatic Stress Disorder (PTSD) (Bryan et al., 2015). Lastly, self-forgiveness has been shown to moderate the association between anger and suicidal behavior (Hirsch, Webb, \& Jeglic, 2012). 


\section{Self-Forgiveness and Spirituality}

Although forgiveness is not a concept exclusive to spirituality, it is a component to most mainstream religions (Webb, Toussaint, \& Conway-Williams, 2012). As such, forgiveness is one factor that offers the potential explanation of an indirect relationship between spirituality and suicidal behaviors. While forgiveness of others has been consistently associated with spirituality (Davis, Worthington, Hook, \& Hill, 2013; Toussaint \& Williams, 2008), self-forgiveness has less consistently displayed a relationship with spirituality (Lyons, Deane, Caputi, \& Kelly, 2011; Toussaint \& Williams, 2008). Lyons et al. found self-forgiveness to be significantly and positively associated with spirituality, which in turn increased meaning in life. Similarly, Davis et al. supported a moderate association of self-forgiveness and spirituality. Despite these findings, Toussaint and Williams failed to support the relationship between self-forgiveness and religious affiliation; however, this discrepancy doesn't necessarily indicate that self-forgiveness is not related to spirituality though it does suggest that ritualistic components of spirituality may not be the mechanism of spirituality that promotes self-forgiveness. Empirical evidence for the association between self-forgiveness and spirituality is still needed and is an aim of the current project.

\section{Self-Forgiveness, Spirituality, and Suicidal Behavior: A Theoretical Model}

Webb et al. (2015) offer a theoretical model of the associations between: a) forgiveness, as a component of spirituality, b) emotionally and philosophically driven psychological distress, termed existangst, and c) suicidal behaviors and substance abuse. Within this model and consistent with prior research, spirituality is conceptualized as a precursor to forgiveness. Forgiveness exhibits a direct relationship with suicidal behavior as well as an indirect association 
through the mediating variable of existangst, such that forgiveness is thought to be associated with less existangst, which in turn is thought to be associated with less suicidal behavior.

Existangst is one distinct category of mediators theorized to be a mechanism of the indirect effect of forgiveness on suicidal behavior (Webb et al., 2015). As previously described, existangst is emotionally and philosophically driven psychological distress, which encompasses the construct of psychache as well as other symptoms such as depression, anxiety, and hopelessness (Webb et al.). Consistent with the literature, these mediating variables are theorized to be positively related to suicidal behaviors and inversely related to forgiveness. Thus, forgiveness is thought to indirectly reduce suicidal behaviors by reducing existangst.

In addition to existangst, Webb et al's. (2015) model incorporates health behaviors, social support, and interpersonal functioning as theoretical mediators in the indirect relationship between forgiveness and suicidal behaviors. These mechanisms are theorized to work in contrast to existangst by exhibiting a positive association with forgiveness and, in turn, a negative relationship with suicidal behavior.

This theoretical model holds important implications for both research and clinical application. The theoretical associations within this model further our understanding of suicidal behaviors and substance abuse and inform the development of clinical interventions such as forgiveness therapy and other interventions (Webb et al., 2015). Additionally, this model lends support for the protective role of spirituality on substance abuse and suicidal behaviors.

The current project proposes an adaptation of the model presented by Webb et al. (2015), such that the direct relationship between spirituality and suicidal behaviors is evaluated based on ritualistic, theistic, and existential dimensions of spirituality. Further, the indirect effects of each dimension of spirituality are examined through the mediating variable of psychache, as in Webb 
et al.'s original model, as well as the addition of self-forgiveness as a serial mediator. These variables are theorized to be associated such that each dimension of spirituality is directly related to suicidal behaviors, and indirectly related to suicidal behaviors through self-forgiveness and psychache, in serial. A visual representation of this model can be seen in Figure 2.

\section{Hypotheses}

Based on the previous literature, the present study hypothesized the following: (1) ritualistic, theistic, and existential dimensions of spirituality will exhibit a statistically significant and positive bivariate association with self-forgiveness, and a negative association with psychache and suicidal behavior; (2) at the multivariable level of analysis, ritualistic, theistic, and existential spirituality will exhibit a statistically significant and negative direct relationship with suicidal behavior as well as a statistically significant indirect relationship with suicidal behavior such that each dimension of spirituality will be associated with higher levels of selfforgiveness, which in turn will be associated with lower levels of psychache. Lower levels of psychache then will be associated with lower levels of suicidal behavior; (3) the degree of the multivariable relationships between spirituality, self-forgiveness, psychache, and suicidal behavior will vary between the ritualistic, theistic, and existential dimensions of spirituality. That is, each dimension of spirituality may not be similarly associated with the other variables of interest in the serial mediation analyses. Indeed, there may be relative differences in the pattern of these associations. For example, ritualistic spirituality may be indirectly associated with suicidal behavior through self-forgiveness and psychache in sequence, whereas theistic spirituality may be indirectly associated with suicidal behavior, but only through psychache. 


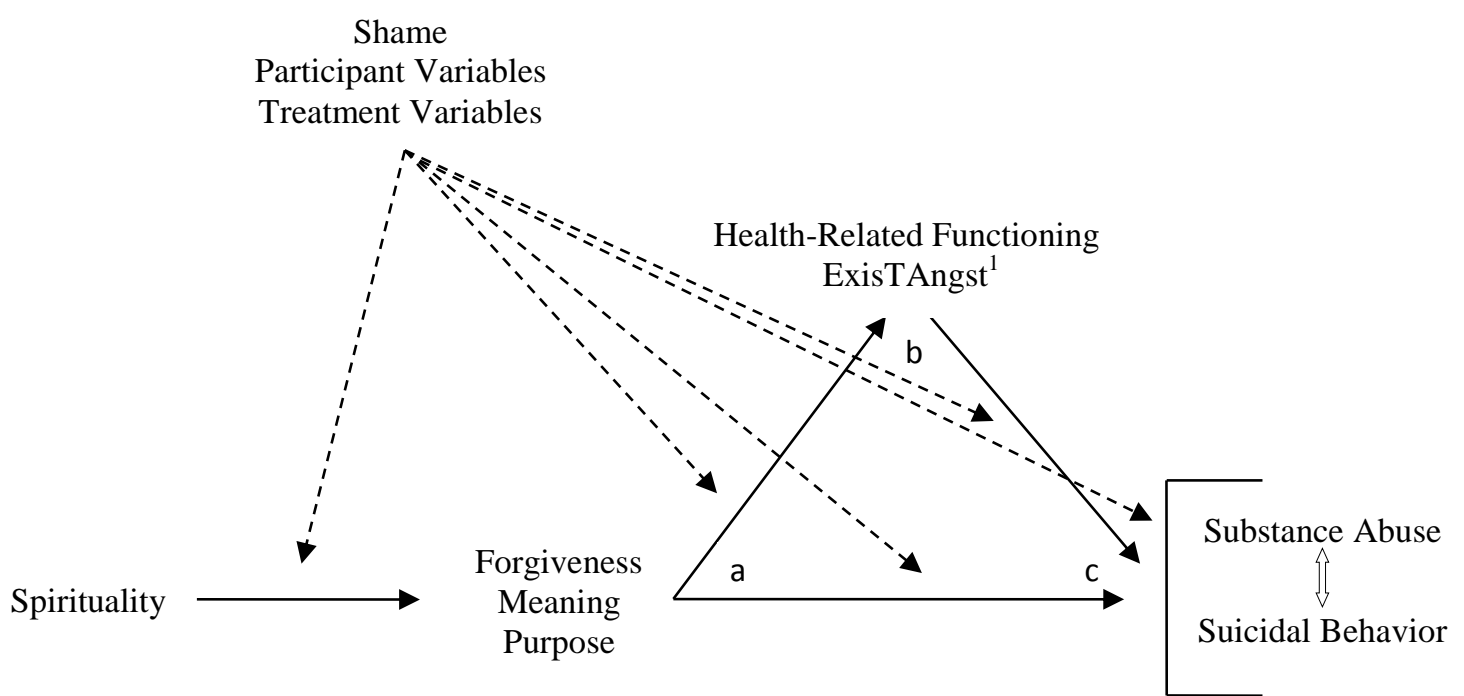

Figure 2.

The Forgiveness-Substance Abuse/Suicidal Behavior Association: A conceptual model (Webb et al., 2015).

${ }^{1}=$ emotionally and philosophically driven psychological distress. For example, symptoms of depression, anxiety, hopelessness, and psychache driven by emotionally charged existential and teleological angst. That is, emotionally struggling with affirming one's meaningful existence $($ Existential + Teleological + Angst $=$ ExisTAngst $) . \mathrm{a} \rightarrow \mathrm{c}=$ Direct effect of forgiveness on dependent variable(s). $a \rightarrow b=$ Direct effect of forgiveness on mediator variable(s). $b \rightarrow c=$ Direct effect of mediator variable(s) on dependent variable(s). $a \rightarrow b \rightarrow c=$ Indirect effect of forgiveness on dependent variable(s) through mediator variable(s). dotted $\rightarrow=$ Moderation effect. $\uparrow=$ Potential for a concomitant, bidirectional effect.

Source Webb et al., 2015 


\section{CHAPTER 2}

\section{METHODS}

\section{Participants}

Participants for the current study were drawn from from a sample of 441 individuals who completed a survey online using Amazon's Mechanical Turk platform. Data was collected from July to August 2016 (see Table 1). Participants were excluded for incompletion or for a completion time of less than 15 minutes. After this exclusion criterion was accounted for, 262 participants were eligible and were used in the present analysis. Each participant was paid \$2 upon adequate completion of the survey. Participants were notified that participation was voluntary and that they could quit the survey at any time. Appropriate IRB approval was acquired before data collection began.

\section{Measures}

Spirituality. Spirituality was measured using the RiTE measure of spirituality (Webb et al., 2014). The RiTE measure consists of thirty self-report items that distribute evenly among the three dimensions of spirituality: ritualistic, theistic, and existential. These items are measured on a 5-point Likert scale anchored by "Strongly Disagree" and "Strongly Agree." A score for each dimension is calculated by summing the scores for each individual item. A total RiTE score can be calculated by summing the scores of each subscale. Higher scores indicate higher levels of spirituality. Possible scores range from 30 to 150 for a total score or 10 to 50 for a subscale score.

The structure of the RiTE measure emerged from exploratory and confirmatory factor analysis of 67 original items (Webb et al., 2014). Excellent reliability was demonstrated in the internal consistency of each subscale of the RiTE model: ritualistic $(\alpha=.92)$, theistic $(\alpha=.98)$, 
existential $(\alpha=.91)$. Convergent and discriminant validity for the RiTE measure was assessed using the Religious Orientation Scale (ROS), the Spiritual Well-Being Scale (SWBS), and the Social Desirability Scale (SDS) (Webb et al., 2014). Ritualistic Spirituality and theistic Spirituality demonstrated convergent validity with the Religious Well-Being subscale of the SWBS as well as the Intrinsic Religiosity subscale of the ROS $(r=.70-.81)$. Ritualistic and theistic Spirituality demonstrated discriminant validity with the Existential Well-Being subscale of the SWBS and the Extrinsic Religiosity subscale of the ROS $(|r|=.02-.33)$. Existential Spirituality demonstrated limited convergent validity with the Existential Well-Being subscale of the SWBS $(r=.39)$ and discriminant validity with the Religious Well-Being subscale of the SWBS, the Intrinsic Religiosity subscale of the ROS, and the Extrinsic Religiosity subscale of the $\operatorname{ROS}(|r|=.06-.29)$.

There is potential for concern among the high correlation between ritualistic and theistic Spirituality as well as similar patterns among their convergent validity; however, the argument is made that the qualitative differences in the theoretical conceptualization of this model offer unique benefits to the measurement of spirituality and a three-factor solution is empirically supported and preferable for this model (Webb et al., 2014). Also, the ritualistic and theistic subscales have been shown to be differentially associated with other variables (Chang et al., 2015; Webb, Phillips, Bumgarner, \& Conway-Williams, 2013).

Self-forgiveness. Self-forgiveness was measured using a six-item subscale from the Heartland Forgiveness Scale (HFS; Thompson et al., 2005). Each item is answered on a 7-point Likert scale that indicates the extent to which the item is true for the respondent. High scores indicate a high level of self-forgiveness. Possible scores for the self-forgiveness subscale range from 6 to 42. Internal consistency of the self-forgiveness subscale of the HFS has been found to 
be acceptable across multiple studies $(\alpha=.72-.76)$, as has test retest reliability for the selfforgiveness subscale ( $\alpha=.72$; Thompson et al., 2005). The HFS has also demonstrated adequate convergent validity with other measures of dispositional forgiveness (Thompson et al., 2005). Further, the HFS has been shown to be associated with variables that are theorized to be related to forgiveness (e.g., increased satisfaction with life, lowered rumination, etc.; Thompson et al., 2005).

Psychache. The current project utilized the psychache scale (Holden et al., 2001). The initial development of the Psychache Scale included 31 items that were consistent with Shneidman's (1993) definition of psychache. Further refinement of the Psychache Scale reduced the measure to 13 items rated on a Likert scale ranging from "Never" to "Always," or "Strongly Disagree" to "Strongly Agree." Possible scores range from 13 to 65 with lower scores indicating lower psychache. These 13 items demonstrated high reliability ( $\alpha=.92$; Holden et al., 2001) indicating high homogeneity among items. The Psychache Scale also demonstrated excellent construct validity, correlating moderately to highly $(r=.33-.65)$ with criteria for suicidal behavior (Holden et al., 2001). Further, psychache contributed unique variance to the prediction of suicidal ideation, suicide attempts, likelihood of future suicide commission, and self-injury (Holden et al., 2001).

Suicidal behavior. The Suicidal Behaviors Questionnaire-Revised (SBQ-R; Osman et al., 2001) is a 4-item measure used to assess suicidal behavior. Osman et al., (2001) provided empirical support for the internal consistency of the SBQ-R $(\alpha=.76)$ as well as its ability to adequately distinguish suicidal individuals from non-suicidal individuals. Possible scores on the SBQ-R range from 3 to 18 . A score of seven was indicated as the most useful cutoff for nonsuicidal individuals with lower scores indicating reduced risk (Osman et al., 2001). 
Overall, the measures used in the present study were deemed to have adequate internal consistency. Alpha coefficients range from .85 for suicidal behavior to .99 for theistic spirituality. These measures are consistent with those reported from the literature above. Alpha coefficients are reported in Table 2.

\section{Statistical Analysis}

In regards to Hypothesis 1, Pearson Product-Moment Correlations were calculated to assess the bivariate association between each dimension of spirituality, self-forgiveness, psychache, and suicidal behavior. Hypothesis 2 was tested through a serial mediation analysis using the SPSS macro, PROCESS (Hayes, 2013). This analysis allowed for the assessment of the direct effect of spirituality on suicidal behavior as well as the indirect effect of spirituality on suicidal behavior through the mediating role(s) of self-forgiveness and psychache. Hypothesis 3 states that each dimension of spirituality will be related to suicidal behavior in varying degrees. In order to assess this, three separate mediation analyses were run with each dimension of spirituality as the independent variable. The alternate dimensions of spirituality were included as covariates at each level of the analysis to control for overlap between dimensions of spirituality. That is and for example, it may be that ritualistic spirituality and existential spirituality are associated with less suicidal behavior, but theistic spirituality is not. A visual representation of this statistical model can be seen in Figure 3.

Considering the use of serial mediation in the current project, a unique challenge exists regarding the use of covariates. Depression and hopelessness have strong empirical ties to suicidal behaviors as well as psychache and, thus, are intuitively implicated as covariates for this analysis; however, Hayes (2013) advises against the use of covariates that could also potentially serve as mediators in the association being tested. Because depression and hopelessness are 


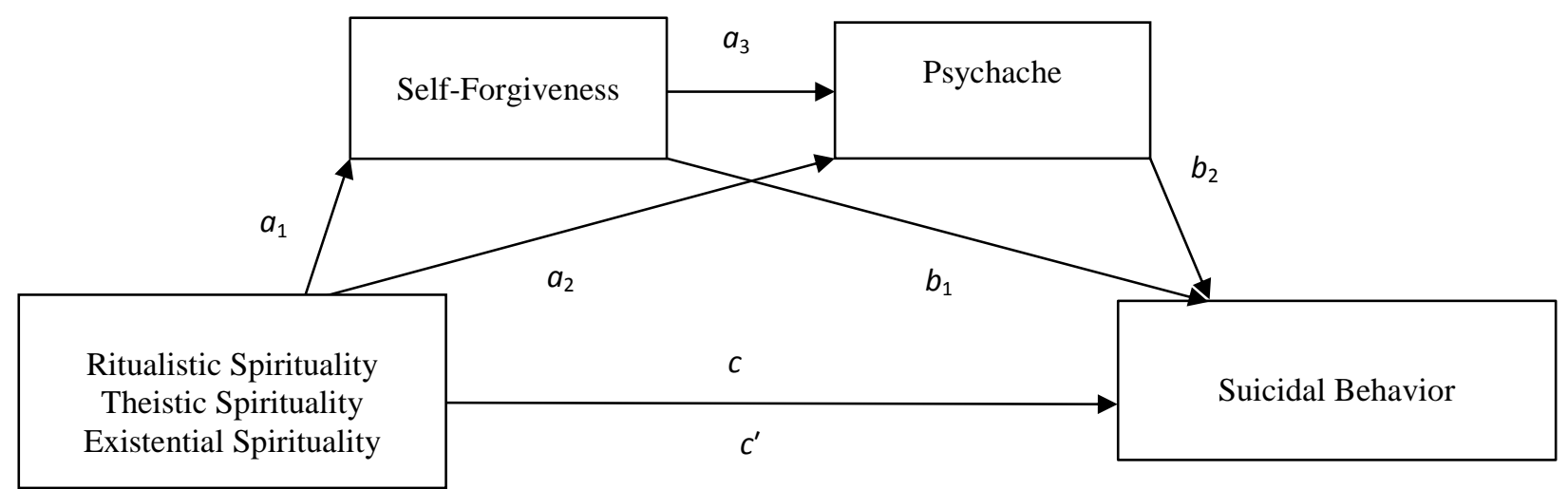

$a_{1} \quad=$ basic association of Spirituality with Self-Forgiveness

$a_{2} \quad=$ basic association of Spirituality with Psychache

$a_{3} \quad=$ basic association of Self-Forgiveness with Psychache

$b_{1} \quad=$ basic association of Self-Forgiveness with Suicidal Behavior

$b_{2} \quad=$ basic association of Psychache with Suicidal Behavior

$c \quad=$ total effect of Spirituality on Suicidal Behavior

$c^{\prime} \quad=$ direct effect of Spirituality on Suicidal Behavior, after accounting for Self-Forgiveness and Psychache

$a b \quad=$ total indirect effect of Spirituality on Suicidal Behavior through Self-Forgiveness and/or Psychache

$a_{1} b_{1} \quad=$ specific indirect effect of Spirituality on Suicidal Behavior through Self-Forgiveness

$a_{2} b_{2} \quad=$ specific indirect effect of Spirituality on Suicidal Behavior through Psychache

$a_{1} a_{3} b_{2}=$ specific indirect effect of Spirituality on Suicidal Behavior through Self-Forgiveness and Psychache, in serial

Figure 3.Hypothesized Serial Mediation Associations 
likely to mediate the relationship between spirituality and suicidal behaviors, controlling for these variables may result in an inaccurate estimate of the direct and indirect effect of spirituality on suicidal behaviors. This is because it is expected that there is shared variance between psychache, depression, and hopelessness and eliminating this shared variance may inaccurately reduce the observed effect of spirituality on suicidal behaviors. That is, covarying depression and hopelessness would result in the estimation of the effect of spirituality on suicidal behaviors having statistically removed the effect of depression and hopelessness from the model, and thus any variance that spirituality may explain in suicidal behavior via depression or hopelessness as mediators. As such, depression and hopelessness, although important factors to consider in the relationship between spirituality and suicidal behaviors, will not be used as covariates in the current project. However, age, gender, ethnicity, and educational level were used as covariates in the analysis.

Regarding statistical power, that is to detect a statistically significant relationship should one exist, the current project utilized bootstrapping in testing indirect effects to reduce the risk of making a Type II error. Bootstrapping is a method of resampling with replacement and was performed 10,000 times, per Hayes' (2013) recommendations. Regarding sample size more generally, Keith (2015) recommends the common rule of thumb of 10-20 participants per independent variable in multiple regression based analyses. As such, it appears that the extant sample size $(\mathrm{n}=262)$ exceeds recommendations for adequate statistical power (Keith, 2015); that is, based on the inclusion of 9 independent variables, mediator variables, and covariates, a sample size of 90 - 180 would be recommended. 


\section{CHAPTER 3}

\section{RESULTS}

\section{Sample Characteristics}

Of the 262 participants who completed the online survey, the majority was white $(78.2 \%$, $\mathrm{N}=205)$ and female $(50.4 \%, \mathrm{~N}=132)$. Agnosticism was the largest shared religious belief among the sample $(24 \%, \mathrm{~N}=63)$ followed by Atheism $(16 \%, \mathrm{~N}=42)$, and Protestantism $(15.3 \%, \mathrm{~N}=40)$. A large portion of the sample was college educated $(39.7 \%, \mathrm{~N}=104)$ and over half of the sample received a high school diploma/GED or a Vocational Degree $(51.5 \%, \mathrm{~N}=135)$. The age of participants ranged from 19 to 73 with an average age of 37.2. Sample characteristics can be seen in Table 1.

\section{Bivariate Correlations}

Ritualistic spirituality was positively related to theistic spirituality $(r=.87, p<.001)$ and existential spirituality $(r=.18, p=.003)$. Theistic spirituality was positively related to existential spirituality $(r=.21, p=.001)$. Existential spirituality was positively related forgiveness of self $(r=$ $.25, p<.001)$ and negatively related to psychache $(r=-.23, p<.001)$ and suicidal behavior $(r=-$ $.20, p=.001)$. Self-forgiveness was negatively associated with both psychache $(r=.58, p<.001)$ and suicidal behaviors $(r=.43, p<.001)$. Psychache was positively related to suicidal behavior $(r=.66, p<.001)$. All other bivariate correlations were statistically non-significant. Bivariate correlations are shown in Table 2.

\section{Multivariable Analyses}

The results from the current analysis were obtained through testing a series of three separate serial mediation models substituting ritualistic, theistic, and existential spirituality as the independent variable. Overall, the variables in each of the models account for $45.8 \%$ of the 
Table 1

Sample Characteristics ( $\mathrm{N}=262)$

\begin{tabular}{|c|c|c|}
\hline Variable & Mean/N & $\begin{array}{c}\text { Percentage/Standard } \\
\text { Deviation }\end{array}$ \\
\hline \multicolumn{3}{|l|}{ Gender } \\
\hline Male & 130 & $49.60 \%$ \\
\hline Female & 132 & $50.40 \%$ \\
\hline Age & 37.18 & 11.62 \\
\hline \multicolumn{3}{|l|}{ Ethnicity } \\
\hline White & 205 & $78.24 \%$ \\
\hline African American & 21 & $8.00 \%$ \\
\hline Hispanic & 20 & $7.60 \%$ \\
\hline Asian & 14 & $5.30 \%$ \\
\hline American Indian & 2 & $0.80 \%$ \\
\hline \multicolumn{3}{|l|}{ Religious Affiliation } \\
\hline Atheist & 42 & $16.03 \%$ \\
\hline Agnostic & 63 & $24.05 \%$ \\
\hline Baptist & 11 & $4.20 \%$ \\
\hline Christian (other) & 37 & $14.12 \%$ \\
\hline Protestant & 40 & $15.27 \%$ \\
\hline Catholic & 32 & $12.21 \%$ \\
\hline Jewish & 4 & $1.53 \%$ \\
\hline Muslim & 2 & $0.76 \%$ \\
\hline Buddhist & 6 & $2.29 \%$ \\
\hline Wiccan & 1 & $0.38 \%$ \\
\hline None & 24 & $9.16 \%$ \\
\hline \multicolumn{3}{|l|}{ Education Level } \\
\hline Doctoral Degree & 7 & $2.67 \%$ \\
\hline Masters Degree & 14 & $5.34 \%$ \\
\hline Bachelors Degree & 104 & $39.69 \%$ \\
\hline Vocational School & 55 & $20.99 \%$ \\
\hline $\begin{array}{r}\text { High School Diploma/ } \\
\text { GED }\end{array}$ & 80 & $30.53 \%$ \\
\hline $\begin{array}{r}\text { Less than High School } \\
\text { Diploma }\end{array}$ & 2 & $0.76 \%$ \\
\hline
\end{tabular}


Table 2

Bivariate Correlations

$\begin{array}{llllllllll}1 & 2 & 3 & 4 & 5 & 6 & 7 & 8 & 9 & 10\end{array}$

\begin{tabular}{|c|c|c|c|c|c|c|c|c|c|c|c|}
\hline 1.) & Gender $^{c}$ & & & & & & & & & & \\
\hline 2.) & Age & .06 & & & & & & & & & \\
\hline 3.) & Education Level & .02 & $.14^{*}$ & & & & & & & & \\
\hline 4.) & Race/Ethnicity ${ }^{\mathrm{b}}$ & -.01 & $-.21 * *$ & .04 & & & & & & & \\
\hline 5.) & Ritualistic Spirituality & $.14^{*}$ & $.13^{*}$ & -.03 & .11 & $(.95)^{\mathrm{a}}$ & & & & & \\
\hline 6.) & Theistic Spirituality & .11 & $.13^{*}$ & -.07 & .09 & $.87 * *$ & $(.99)$ & & & & \\
\hline 7.) & Existential Spirituality & $.18 * *$ & .05 & -.09 & .02 & $.18 * *$ & $.21 * *$ & $(.88)$ & & & \\
\hline 8.) & Forgiveness of Self & .07 & .04 & .05 & $.13^{*}$ & -.04 & -.06 & $.25 * *$ & $(.88)$ & & \\
\hline 9.) & Psychache & -.08 & -.05 & -.11 & -.10 & .04 & .06 & $-.23 * *$ & $-.58 * *$ & $(.97)$ & \\
\hline 10.) & Suicidal Behaviors & $-.14 *$ & -.12 & -.12 & -.03 & -.03 & -.03 & $-.20 * *$ & $-.43 * *$ & $.66^{* *}$ & $(.82)$ \\
\hline
\end{tabular}

** Correlation is significant at the 0.01 level (2-tailed).

* Correlation is significant at the 0.05 level (2-tailed).

${ }^{a}$ Numbers in parentheses are estimates of internal consistency (Cronbach's $\alpha$ )

${ }^{\mathrm{b}}$ Ethnicity: 0 = White; 1 = Non-white

${ }^{\mathrm{c}}$ Gender: $0=$ Male; 1 = Female 
variance in suicidal behavior scores $\left(\mathrm{F}(9,252)=18.95, R^{2}=.4578, p<.0001\right)$. Before accounting for self-forgiveness and psychache, the total effect (i.e., each dimension of spirituality and all covariates) accounted for approximately $8 \%$ of the variance in suicidal behaviors $\left(R^{2}=.0794, p\right.$ $=.0222)$. Thus, self-forgiveness and psychache contribute approximately $38 \%$ of the variance accounted for in suicidal behavior scores $\left(R^{2} \Delta=.3784\right)$. Regarding various dimensions of spirituality, ritualistic spirituality was non-significantly related to self-forgiveness $\left(a_{1}=.02\right)$ and psychache $\left(a_{2}=-.00\right)$. Ritualistic spirituality also failed to exhibit a total $(c=.01)$ or direct $\left(c^{\prime}=\right.$ $.02)$ effect on suicidal behavior $(=.02)$. Across all models tested, self-forgiveness was negatively related to psychache $\left(a_{3}=-.81, p<.0001\right)$, but was non-significantly related to suicidal behavior $\left(b_{1}=-.03\right)$. Psychache was significantly associated with suicidal behaviors $\left(b_{2}=.16, p<.0001\right)$. There were no observed indirect effects of Ritualistic Spirituality on Suicidal Behaviors (i.e., $a b$, $\left.a_{1} b_{1}, a_{2} b_{2}, a_{1} a_{3} b_{2}\right)$.

In the second model tested, theistic spirituality was non-significantly related to both selfforgiveness $\left(a_{1}=-.09\right)$ and psychache $\left(a_{2}=.04\right)$. There were no observed total $(c=-.00)$, direct $\left(c^{\prime}=-.02\right)$, or indirect effects of theistic spirituality on suicidal behaviors.

In the third model, existential spirituality was statistically significantly related to selfforgiveness $\left(a_{1}=.35, p<.0001\right)$ and suicidal behavior $(c=-.10, p<.01)$ but not psychache $\left(a_{2}=\right.$ -.21). After controlling for self-forgiveness and psychache in the total effect of existential spirituality on suicidal behavior, the statistical significance observed in the total effect was reduced to non-significance in a test of the direct effect of existential spirituality on suicidal behavior $\left(c^{\prime}=-.01\right)$. This finding indicates a mediating effect through either one or both of the proposed mediators (i.e., self-forgiveness and/or psychache). Further evaluation of the indirect effects of existential spirituality on suicidal behavior revealed a significant total indirect effect 
Table 3

Multivariable Associations in the Context of Ritualistic Spirituality

\begin{tabular}{llllll}
\hline Path & Effect & LLCI & ULCI & $S E$ & $p$-value \\
\hline \multicolumn{1}{l}{} & & & & & \\
$c^{\prime}$ & .0123 & -.0609 & .0854 & .0371 & .7416 \\
& .0159 & -.0397 & .0715 & .0282 & .5739 \\
$a_{1}$ & & & & & \\
$a_{2}$ & .0226 & -.1333 & .1785 & .0792 & .7755 \\
$\boldsymbol{a}_{\mathbf{3}}$ & -.0001 & -.2320 & .2318 & .1178 & .9991 \\
$b_{1}$ & $\mathbf{- . 8 1 4 8}$ & $\mathbf{- . 9 9 2 2}$ & $\mathbf{- . 6 3 7 4}$ & $\mathbf{. 0 9 0 1}$ & $<.0001$ \\
$\boldsymbol{b}_{\mathbf{2}}$ & -.0293 & -.0763 & .0177 & .0239 & .2205 \\
& $\mathbf{. 1 6 0 8}$ & $\mathbf{. 1 2 5 3}$ & $\mathbf{. 1 9 6 3}$ & $\mathbf{. 0 1 8 0}$ & $<.0001$ \\
$a b$ & & & & & \\
$a_{1} b_{1}$ & -.0036 & -.0493 & .0410 & .0227 & - \\
$a_{1} a_{3} b_{2}$ & -.0007 & -.0099 & .0036 & .0030 & - \\
$a_{2} b_{2}$ & -.0030 & -.0248 & .0175 & .0106 & - \\
\hline
\end{tabular}

\footnotetext{
$a_{1} \quad=$ basic association of Ritualistic Spirituality with Self-Forgiveness

$a_{2} \quad=$ basic association of Ritualistic Spirituality with Psychache

$a_{3} \quad=$ basic association of Self-Forgiveness with Psychache

$b_{1} \quad=$ basic association of Self-Forgiveness with Suicidal Behavior

$b_{2} \quad=$ basic association of Psychache with Suicidal Behavior

$c \quad=$ total effect of Ritualistic Spirituality on Suicidal Behavior, before accounting for Self-Forgiveness and Psychache

$c^{\prime} \quad=$ direct effect of Ritualistic Spirituality on Suicidal Behavior, after accounting for Self-Forgiveness and Psychache

$a b \quad=$ total indirect effect of Ritualistic Spirituality on Suicidal Behavior through Self-Forgiveness and/or Psychache

$a_{1} b_{1} \quad=$ specific indirect effect of Ritualistic Spirituality on Suicidal Behavior through Self-Forgiveness

$a_{2} b_{2} \quad=$ specific indirect effect of Ritualistic Spirituality on Suicidal Behavior through Psychache

$a_{1} a_{3} b_{2}=$ specific indirect effect of Ritualistic Spirituality on Suicidal Behavior through Self-Forgiveness and Psychache, in serial

LLCI = lower limit confidence interval

UPCI = upper limit confidence interval

SE $\quad=$ standard error
} 
Table 4

Multivariable Associations in the Context of Theistic Spirituality

\begin{tabular}{llllll}
\hline Path & Effect & LLCI & ULCI & $S E$ & $p$-value \\
\hline$c$ & & & & & \\
$c^{\prime}$ & -.0028 & -.0610 & .0555 & .0296 & .9258 \\
& -.0230 & -.0691 & .0231 & .0234 & .3274 \\
$a_{1}$ & & & & & \\
$a_{2}$ & -.0880 & -.2126 & .0365 & .0632 & .1650 \\
$\boldsymbol{a}_{\mathbf{3}}$ & .0380 & -.1522 & .2281 & .0966 & .6945 \\
$b_{1}$ & $\mathbf{- . 8 1 4 8}$ & $\mathbf{- . 9 9 2 2}$ & $\mathbf{- . 6 3 7 4}$ & $\mathbf{. 0 9 0 1}$ & $<.0001$ \\
$\boldsymbol{b}_{\mathbf{2}}$ & -.0293 & -.0763 & .0177 & .0239 & .2205 \\
& $\mathbf{. 1 6 0 8}$ & $\mathbf{. 1 2 5 3}$ & $\mathbf{. 1 9 6 3}$ & $\mathbf{. 0 1 8 0}$ & $<.0001$ \\
$a b$ & & & & & \\
$\mathrm{a}_{1} \mathrm{~b}_{1}$ & .0202 & -.0136 & .0570 & .0180 & - \\
$a_{1} a_{3} b_{2}$ & .0026 & -.0011 & .0124 & .0031 & - \\
$a_{2} b_{2}$ & .0115 & -.0047 & .0304 & .0088 & - \\
\hline
\end{tabular}

\footnotetext{
$a_{1} \quad=$ basic association of Theistic Spirituality with Self-Forgiveness

$a_{2} \quad=$ basic association of Theistic Spirituality with Psychache

$a_{3} \quad=$ basic association of Self-Forgiveness with Psychache

$b_{1} \quad=$ basic association of Self-Forgiveness with Suicidal Behavior

$b_{2} \quad=$ basic association of Psychache with Suicidal Behavior

$c \quad=$ total effect of Theistic Spirituality on Suicidal Behavior

$c^{\prime} \quad=$ direct effect of Theistic Spirituality on Suicidal Behavior, after accounting for Self-Forgiveness and Psychache

$a b=$ total indirect effect of Theistic Spirituality on Suicidal Behavior through Self-Forgiveness and/or Psychache

$a_{1} b_{1} \quad=$ specific indirect effect of Theistic Spirituality on Suicidal Behavior through Self-Forgiveness

$a_{2} b_{2} \quad=$ specific indirect effect of Theistic Spirituality on Suicidal Behavior through Psychache

$a_{1} a_{3} b_{2}=$ specific indirect effect of Theistic Spirituality on Suicidal Behavior through Self-Forgiveness and Psychache, in serial

LLCI = lower limit confidence interval

UPCI = upper limit confidence interval

$S E \quad=$ standard error
} 
Table 5

Multivariable Associations in the Context of Existential Spirituality

\begin{tabular}{llllll}
\hline Path & Effect & LLCI & ULCI & $S E$ & $p$-value \\
\hline & & & & & \\
$c$ & $\mathbf{- . 1 0 2 4}$ & $\mathbf{- . 1 7 7 0}$ & $\mathbf{- . 0 2 7 8}$ & $\mathbf{. 0 3 7 9}$ & $\mathbf{. 0 0 7 3}$ \\
$c^{\prime}$ & -.0131 & -.0677 & .0415 & .0277 & .6375 \\
& & & & & \\
$\boldsymbol{a}_{\mathbf{1}}$ & $\mathbf{. 3 4 9 7}$ & $\mathbf{. 1 8 5 7}$ & $\mathbf{. 5 1 3 7}$ & $\mathbf{. 0 8 3 3}$ & $<.0001$ \\
$a_{2}$ & -.2068 & -.4345 & .0209 & .1156 & .0749 \\
$\boldsymbol{a}_{\mathbf{3}}$ & $\mathbf{- . 8 1 4 8}$ & $\mathbf{- . 9 9 2 2}$ & $\mathbf{- . 6 3 7 4}$ & $\mathbf{. 0 9 0 1}$ & $<.0001$ \\
$b_{1}$ & -.0293 & -.0763 & .0177 & .0239 & .2205 \\
$\boldsymbol{b}_{\mathbf{2}}$ & $\mathbf{. 1 6 0 8}$ & $\mathbf{. 1 2 5 3}$ & $\mathbf{. 1 9 6 3}$ & $\mathbf{. 0 1 8 0}$ & $<.0001$ \\
& & & & & \\
$\boldsymbol{a b}$ & $\mathbf{- . 0 8 9 3}$ & $\mathbf{- . 1 3 4 3}$ & $\mathbf{- . 0 4 8 9}$ & $\mathbf{. 0 2 1 7}$ & - \\
$a_{1} b_{1}$ & -.0102 & -.0297 & .0052 & .0087 & - \\
$\boldsymbol{a}_{\mathbf{1}} \boldsymbol{a}_{\mathbf{3}} \boldsymbol{b}_{\mathbf{2}}$ & $\mathbf{- . 0 4 5 8}$ & $\mathbf{- . 0 7 7 7}$ & $\mathbf{- . 0 2 5 0}$ & $\mathbf{. 0 1 3 3}$ & - \\
$a_{2} b_{2}$ & -.0333 & -.0713 & .0038 & .0187 & - \\
\hline
\end{tabular}

\footnotetext{
$a_{1} \quad=$ basic association of Existential Spirituality with Self-Forgiveness

$a_{2} \quad=$ basic association of Existential Spirituality with Psychache

$a_{3} \quad=$ basic association of Self-Forgiveness with Psychache

$b_{1} \quad=$ basic association of Self-Forgiveness with Suicidal Behavior

$b_{2} \quad=$ basic association of Psychache with Suicidal Behavior

$c \quad=$ total effect of Existential Spirituality on Suicidal Behavior

$c^{\prime} \quad=$ direct effect of Existential Spirituality on Suicidal Behavior, after accounting for Self-Forgiveness and Psychache

$a b=$ total indirect effect of Existential Spirituality on Suicidal Behavior through Self-Forgiveness and/or Psychache

$a_{1} b_{1}=$ specific indirect effect of Existential Spirituality on Suicidal Behavior through Self-Forgiveness

$a_{2} b_{2} \quad=$ specific indirect effect of Existential Spirituality on Suicidal Behavior through Psychache

$a_{1} a_{3} b_{2}=$ specific indirect effect of Existential Spirituality on Suicidal Behavior through Self-Forgiveness and Psychache, in serial

LLCI = lower limit confidence interval

UPCI = upper limit confidence interval

$S E \quad=$ standard error
} 
$(a b=-.09,95 \mathrm{CI}=-.13,-.05)$, which is accounted for by the specific indirect effect of existential spirituality on suicidal behavior through self-forgiveness and psychache, in serial $\left(a_{1} a_{3} b_{2}=-.05\right.$, $95 \mathrm{CI}=-.08,-.03)$. That is, higher levels of existential spirituality were associated with higher levels of self-forgiveness, which in turn were associated with lower levels of psychache, which were associated with lower levels of suicidal behavior. Neither self-forgiveness nor psychache were significant sole mediators in this model.

\section{Review of Hypotheses}

In regards to the first hypothesis, the results fail to confirm that each dimension of spirituality is positively related to self-forgiveness and negatively related to psychache and suicidal behavior. Only existential spirituality shared a statistically significant relationship with these variables consistent with the hypothesized direction.

The second hypothesis also was not fully supported as neither ritualistic nor theistic spirituality exhibited a direct or indirect relationship with suicidal behavior. Existential spirituality did, however, exhibit such a relationship as reported above.

The third and final hypothesis was supported in that each dimension of spirituality differed in the degree of its relationship to other variables in the model. That is, ritualistic, theistic, and existential Spirituality are relatively different in the extent to which they relate to other variables in the model. For example, and of primary interest to this study, only existential spirituality exhibited an indirect association with suicidal behavior, operating through selfforgiveness and psychache, in serial. Moreover, neither ritualistic spirituality nor theistic spirituality exhibited direct or indirect associations with suicidal behavior. 


\section{CHAPTER 4}

\section{DISCUSSION}

Consistent with the extant literature, the current study generally supports the notion that some aspects of spirituality play a protective role against suicidal behavior; however, the dimensions of spirituality that play a role in this association may not be as far reaching as expected based on previous research. Self-forgiveness also played an important role in reducing suicidal behavior, though this relationship was indirect such that self-forgiveness reduces psychache, which in turn reduces suicidal behavior. Further, existential spirituality was the only dimension of spirituality to serve as a precursor to this relationship, which was not expected given the previously reviewed literature. These associations will be explored in more detail below.

\section{Spirituality and Suicidal Behavior}

Ritualistic Spirituality. Previous literature lends support for religion's tendency to reduce suicidal behavior (Rasic, Kisely, \& Langille, 2011; Seigrist, 1996) making the results of the present study challenging to interpret as ritualistic spirituality was not observed to have a significant multivariable or bivariate association in the present study. As previously mentioned, one distinguishing feature of the current study is the dissection of spirituality through the tridimensional RiTE model. By evaluating the ritualistic, theistic, and existential components of spirituality individually while controlling for alternative dimensions, the potential for a cumulative effect of these dimensions is removed. While this explanation does not explain the absence of a bivariate relationship between ritualistic spirituality and suicidal behaviors in the present study, it offers an important consideration for previous literature citing the protective role of religion against suicide. 
Further research is needed to evaluate the effect of purely ritualistic aspects of religion on suicidal behaviors. If the results of the present study are supported by future research (i.e., a nonsignificant relationship between ritualistic spirituality and suicidal behavior), it may be that the purpose and meaning derived from spirituality (i.e., existential aspects of spirituality) are the most important protective qualities in relation to suicidal behaviors.

Theistic Spirituality. Similar to ritualistic spirituality, the current study fails to support an association between theistic spirituality and suicidal behavior. One explanation for the failure to observe a significant relationship between both ritualistic spirituality and theistic spirituality concerns the high correlation between these dimensions of spirituality. Generally speaking, a belief in deity or deities (i.e., theistic spirituality) is accompanied by behaviors consistent with those beliefs (i.e., ritualistic spirituality). This is supported by the high correlation between ritualistic and theistic Spirituality in this study $(r=.87)$. Thus, it is possible that the beneficial effects of these dimensions on health are related to both a belief in deity or deities and ritualistic behaviors consistent with those beliefs but not one or the other. By controlling for one dimension of spirituality while testing the other, any observable cumulative effect between ritualistic and theistic spirituality was removed from the equation. Thus, ritualistic spirituality may not be associated with greater self-forgiveness and less psychache and suicidal behavior for individuals who are not fully committed to the beliefs that underlie their ritualistic behaviors. Similarly, a belief in deity or deities may not promote self-forgiveness and protect against psychache and suicidal behavior without behaviors that are consistent with those beliefs.

As with religious behaviors, a belief in a deity or deities may not inherently protect against suicidal behavior. One possible explanation for this finding is that some individuals may hold a belief in a deity or deities but not behave in accordance with their beliefs. Indeed, 
preliminary evidence supports the notion that religious hypocrisy (i.e., "a rational strategy through which religious people seek to minimize and/or delay the costs of the exchange relationship with their god(s) while still getting access to the religious rewards"; Wollschleger \& Beach, 2011, p. 3) is prevalent among religious fundamentalists. Theoretical assertions suggest that such cognitive dissonance is detrimental to psychological well-being (Wollschleger \& Beach, 2011). In a broader context, the incongruence of moral values and behaviors has been termed moral injury (Litz et al., 2009) and may place individuals at a greater risk of suicide. Nevertheless, the high correlation between theistic and ritualistic spirituality $(r=.87)$ in the current study suggests that the proportion of individuals who act against their theistic beliefs is small and would likely not wholly account for the non-significant relationship between theistic spirituality and suicidal behavior.

Existential Spirituality. Existential spirituality exhibited a statistically significant relationship with suicidal behavior. This association can be accounted for by the role of selfforgiveness and psychache as mediators of the relationship. This finding suggests that the meaning and purpose drawn from spirituality may be the most protective feature of spirituality against suicidal behavior. Further, existential spirituality protects against suicidal behavior by promoting self-forgiveness, which in turn is associated with less psychache leading to lower suicidal behavior. This association will be further explored below.

\section{Spirituality and Self-forgiveness}

Neither ritualistic nor theistic spirituality were significantly related to self-forgiveness. This finding was particularly surprising given the emphasis placed on forgiveness in most major world religions (Webb et al., 2012). This could potentially be a result of self-forgiveness being a purely intrapersonal concept and may not be motivated by extraneous factors such as religion. In 
contrast, meaning and purpose in life are also intrapersonal concepts that may promote selfforgiveness (Walmsley \& McCormack, 2016) as was supported in the current study. Individuals who seek meaning and purpose in life may be more motivated to pursue self-forgiveness as it helps remove barriers that interfere with finding meaning and purpose (e.g., problematic drinking [Lyons et al., 2011]; guilt [Carpenter, Tignor, Tsang, \& Willett, 2016]).

\section{Spirituality and Psychache}

Following the pattern of associations described above, ritualistic and theistic spirituality failed to exhibit a significant relationship with psychache. This result may be explained by reasons previously stated. By distinguishing the theistic and ritualistic aspects of spirituality and controlling for the alternatives, the potential for observing an interaction effect is removed. Therefore, it is unclear whether these variables would have an effect on psychache if they were considered together. Existential spirituality also failed to exhibit a significant bivariate associate with psychache. Given the existential nature of psychache described by Shneidman (1993), this finding was also particularly surprising. It is possible that this finding can be explained using the foundations of terror management theory (Greenberg \& Arndt, 2012). This theory is driven by the uniquely human capacity for self-awareness, which illuminates the threats of human existence. Similarly, individuals who contain high levels of existential spirituality may be more acutely aware of existential threats that cause terror. This sense of existential angst may balance out the purpose and meaning that would otherwise protect against psychache.

\section{Self-Forgiveness and Psychache}

Self-forgiveness and psychache, respectively, were shown to operate as serial mediators of the relationship between existential spirituality and suicidal behaviors. Given the absence of research linking self-forgiveness and psychache, this finding is a particularly unique contribution 
to the study of suicide. The finding that existential spirituality reduces suicidal behavior through both mediators serially, but not one or the other individually, is an interesting result with several implications.

First, the fact that self-forgiveness does not serve as a sole mediator of the association between existential spirituality and suicidal behavior in a model with psychache lends support for Shneidman's theory of psychache as suicide (1993). Shneidman's theory states that psychache is the primary cause of suicide; that is, depression, hopelessness, and other contributors of suicide are related only to the extent that they increase psychache. Without psychache, there is no suicide. Thus, when removing the effect of psychache while testing for the mediating effect of self-forgiveness alone, it would be expected that any variation left in suicidal behavior would be minimal and difficult to statistically account for.

Second, this finding lends support to an adaptation of the model proposed by Webb et al. (2015) in that psychache serves as a mediator in the relationship between self-forgiveness and suicidal behavior. Further, existential spirituality is a precursor to the relationship between selfforgiveness and suicidal behaviors, consistent with the model's assertion that spirituality serves as a precursor to the relationship between the variables being modeled. As Webb and colleagues proposed, the current study supports the theory that higher levels of forgiveness, namely selfforgiveness, are associated with lower levels of deep psychological distress (i.e., psychache), which in turn is associated with lower suicidal behavior scores.

Lastly, this finding offers direction for clinical interventions aimed at reducing suicidal behaviors. The current study supports psychache as a significant factor related to suicidal behaviors highlighting its importance as a target in clinical interventions. Further, the current study provides evidence for the potentially protective factor of self-forgiveness against suicidal 
behaviors by decreasing psychache. Forgiveness therapy has proven to be an effective intervention that, while lacking investigation in the context of suicidal behaviors and psychache, has been shown to reduce symptoms such as depression, anxiety, and anger (Lin, Mack, Enright, Krahn, \& Baskin, 2004; Reed \& Enright, 2006). Forgiveness Therapy in the context of this research has largely considered interpersonal forgiveness as a focus of therapy. Although selfforgiveness is linked to psychological well-being (Wohl, DeShea, \& Wahkinney, 2008; Davis et al., 2015), interventions promoting self-forgiveness have been less studied; however, the available support for the promotion of self-forgiveness in therapy is promising (Scherer, Worthington, Hook, \& Campana, 2011).

More mainstream therapies also incorporate components related to or promoting of selfforgiveness. To understand the relevance of self-forgiveness in these therapies, it is useful to highlight concepts related to self-forgiveness. For example, self-compassion is a related construct that has been proposed as a major step in achieving self-forgiveness (Enright, 1996). Self-compassion has been considered a form of self-acceptance (Neff, Rude, \& Kirkpatrick, 2007), which is major component of a third wave cognitive behavioral therapy called Acceptance and Commitment Therapy (ACT). Further, self-acceptance has been considered a necessary component of self-forgiveness (Hall \& Fincham, 2005). Thus, the extant literature points to the importance of self-forgiveness in ACT, though it is not a formal component of this therapy. The current study's support for the previously discussed theoretical model proposed by Webb et al. (2015) allows for the extension of the implications for clinical interventions reported by Webb and colleagues. For example, Webb et al. suggest that "incorporating forgiveness and spirituality into the otherwise traditional psychological practice(s) of psychotherapy may have a cumulative effect—greater than the effect of either alone" (p. 54). Building on this suggestion, 
the current study implicates, specifically, existential aspects of spirituality and self-forgiveness as a potentially relevant component to clinical interventions. That is not to say that clinical interventions should attempt to foster existential spirituality in individuals who don't hold this worldview, but rather that it should be seen as a protective factor that promotes self-forgiveness and should be capitalized on as a catalyst in therapy. Humanistic and Existential therapies such as Logotherapy (Frankl, 1985) may enhance existential spirituality and, in turn, promote selfforgiveness by fostering the ability for individuals to make meaning in their lives.

The role of psychache as a mediator as proposed in Webb at el.'s model was also supported by the current study. As previously stated, psychache may be an important target for therapy with individuals who express suicidal ideation or behaviors. Thus, it may be relevant to explore the biological, socio-cultural, sociological, interpersonal, intrapsychic, logical, conscious and unconscious, and philosophical elements previously described that contribute to suicidal behaviors when working with these individuals.

The clinical efficacy of self-forgiveness and related concepts in the previously mentioned clinical interventions may be related to its ability to alleviate the burden of intrapersonal struggles inherent in psychache such as shame and guilt (Carpenter et al., 2016). Although not empirically explored in the literature, Shneidman (1985) posits that excessively felt shame and guilt are core features of psychache. Thus, self-forgiveness and psychache are, perhaps, related through their mutual connection to intrapersonal variables such as shame and guilt.

\section{Limitations}

The current study offers a unique contribution to the exploration of the connection between spirituality and suicidal behaviors; however, it is prudent to give adequate consideration to the limitations of the present study. First, the present study excluded the use of depression and 
hopelessness as covariates in the analysis (see previous discussion; p. 30). While this was judged to be the most methodologically sound practice, it may be argued that this imposes a significant limitation to the current study. Given that depression and hopelessness share considerable variance with psychache in predicting suicide, it is unclear what amount of variance in suicidal behavior is accounted for by psychache in isolation from depression and hopelessness in the current study.

A second limitation of the present study involves the overlap of ritualistic and theistic spirituality. Although sufficient evidence has supported the three-factor solution of the RiTE model (Webb et al., 2014), it is still arguable that theistic and ritualistic Spirituality are best understood as complimentary components of spirituality that generally occur together, and any effect of spirituality on an outcome usually involves both of these domains. While the speculation that ritualistic and theistic spirituality are generally complementary components of spirituality is unfounded in the literature, theoretical assertions suggest deleterious effects when these domains of spirituality are inconsistent (Wollschleger, \& Beach, 2011). That is, holding a belief in a deity or deities but not acting consistently with this belief may have a negative impact on mental and physical functioning. Thus, as previously stated, by removing the effect of one of these dimensions when testing the other, the potential for observing a cumulative effect is removed.

Thirdly, the use of self-report data is inherently limiting. Despite the confidential nature of the data collection process, the data are still susceptible to the effects of social desirability (which was not measured). Additionally, the monetary incentive for completing the online survey provides motivation to complete the survey as quickly as possible without paying mind to the content of the survey. This consideration led to the inclusion criteria that respondents must 
have a completion time of greater than 15 minutes in order to be included in the study. The 15 minute value was subjectively deemed an appropriate response time based on a trial survey completed by the author; however this criteria may be argued as arbitrary lending an addition limitation to the present study.

A fourth limitation involves the assumed directionality of the effect between spirituality and self-forgiveness. That is, it may be argued that there is not enough theoretical support for the notion that spirituality necessarily precedes self-forgiveness as the statistical model being tested suggests. Because self-forgiveness is not a concept exclusive to spirituality, it is arguable that there is lacking evidence that spirituality precedes self-forgiveness in time. Although the rationale for this assumption of direction is based on a previous theoretical model (i.e., Webb et al., 2015), it may be argued that self-forgiveness cannot replace interpersonal forgiveness in the original model because interpersonal forgiveness is explicitly included in most mainstream religions (Webb et al., 2012) while self-forgiveness is not.

A fifth limitation regards a possible self-selection bias, evidenced by the disproportionate representation of Atheists and Agnostics in the present study. That is, something inherent in the current study may have attracted this population to participate. Atheists and Agnostics, combined, accounted for approximately $40 \%$ of the participants in the current study, which grossly misrepresents the distribution in the U.S. population, of which Atheists and Agnostics account for approximately $7 \%$ (Smith \& Cooperman, 2015). Given the misrepresentation of the sample, the effect of ritualistic and theistic spirituality on suicidal behavior may have been distorted. Considering that nearly half the sample is suspected of reporting low levels of ritualistic and theistic spirituality, it would be expected that the associations exhibited by these 
variables would be distorted. The high correlation of ritualistic and theistic spirituality may also be attributable to the misrepresentative sample.

Lastly and most importantly, the use of cross-sectional data limits the level of causal influence implicated in the present analysis. The rationale for the statistical methods is largely based on theoretical models and past empirical support. Nonetheless, the nature of the present study does not allow for an observation of causal relationships.

\section{Conclusions and Future Directions}

The current study contributes to the literature on spirituality and suicidal behavior. Further, the inclusion of self-forgiveness and psychache as mediators offers a novel exploration of the link between spirituality and suicidal behaviors. Psychache was supported as a factor significantly related to suicidal behaviors and self-forgiveness was implicated as a potential buffer of psychache. Future research should consider longitudinal and experimental designs to provide a more methodologically rigorous method of testing causal relationships. Additionally, the use or development of scales that combine dimensions of spirituality in the RiTE model may provide a better understanding of the potential cumulative effects of various dimensions of spirituality on other variables.

Literature has supported spirituality as an important factor that protects against a range of mental and physical health issues. This support has led to the consideration of spirituality as a protective factor against suicide. The growing support for psychache points to its significance as a precipitant to suicidal behaviors. The relationship between psychache and spirituality is an area that warrants more attention in the literature, as spirituality may provide a protective buffer from the influence of psychache. Spirituality is a powerful human experience that has the potential to significantly influence health and well-being and warrants more attention as such. The current 
study contributes to the support of this notion in that spirituality was shown to be positively related to self-forgiveness, which in turn was negatively associated with psychache, which shared a positive relationship with suicidal behavior. While the current study contributes to the literature on spirituality's influence on suicidal behaviors, it leaves many questions left to be explored related to spirituality and health. 


\section{REFERENCES}

Ai, A. L., Ladd, K. L., Peterson, C., Cook, C. A., Shearer, M., \& Koenig, H. G. (2010). Longterm adjustment after surviving open heart surgery: The effect of using prayer for coping replicated in a prospective design. The Gerontologist, 50(6), 798-809.

doi:10.1093/geront/gnq046

Aish, A. M., \& Wasserman, D. (2001). Does Beck's Hopelessness Scale really measure several components?. Psychological medicine, 31(02), 367-372.

doi:10.1017/S0033291701003300

Allport, G. W., \& Ross, J. M. (1967). Personal religious orientation and prejudice. Journal of Personality and Social Psychology, 5, 432-443. doi:10.1037/h0021212

Altemeyer, B., \& Hunsberger, B. (2004). Research: A revised religious fundamentalism scale: The short and sweet of it. The International Journal for the Psychology of Religion, 14(1), 47-54. doi:10.1207/s15327582ijpr1401_4

Austin, D., \& Lennings, C. J. (1993). Grief and religious belief: Does belief moderate depression?. Death Studies, 17(6), 487-496. doi:10.1080/07481189308252634

Bahk, Y. C., Han, E., \& Lee, S. H. (2014). Biological rhythm differences and suicidal ideation in patients with major depressive disorder. Journal of Affective Disorders, 168, 294-297. doi:10.1016/j.jad.2014.07.001

Balbuena, L., Baetz, M., \& Bowen, R. (2013). Religious attendance, spirituality, and major depression in Canada: a 14-year follow-up study. The Canadian Journal of Psychiatry, $58(4), 225-232$.

Beck, A. T. (1962). Cognitive therapy and the emotional disorders. New York: Meridian Books 
Beck, A. T., Weissman, A., Lester, D., \& Trexler, L. (1974). The measurement of pessimism: The Hopelessness Scale. Journal of Consulting and Clinical Psychology, 42, 861-865. doi: $10.1037 / \mathrm{h} 0037562$

Berg, C., Choi, W. S., Kaur, H., Nollen, N., \& Ahluwalia, J. S. (2009). The roles of parenting, church attendance, and depression in adolescent smoking. Journal of Community Health, 34(1), 56-63. doi:10.1007/s10900-008-9118-4

Berlim, M. T., Mattevi, B. S., Pavanello, D. P., Caldieraro, M. A., Fleck, M., Wingate, L. R., \& Joiner, T. E. (2003). Psychache and suicidality in adult mood disordered outpatients in Brazil. Suicide and Life-Threatening Behavior, 33(3), 242-248. doi:10.1521/suli.33.3.242.23220

Berry, D. M., \& York, K. (2011). Depression and religiosity and/or spirituality in college: A longitudinal survey of students in the USA. Nursing \& Health Sciences, 13(1), 76-83. doi:10.1111/j.1442-2018.2011.00584.x

Blazer, D. (2012). Religion/spirituality and depression: What can we learn from empirical studies?. American Journal of Psychiatry, 169(1), 10-12. doi:10.1176/appi.ajp.2011.11091407

Boelens, P. A., Reeves, R. R., Replogle, W. H., \& Koenig, H. G. (2012). The effect of prayer on depression and anxiety: maintenance of positive influence one year after prayer intervention. The International Journal of Psychiatry in Medicine, 43(1), 85-98. doi:10.2190/PM.43.1.f

Britton, P. C., Stephens, B., Wu, J., Kane, C., Gallegos, A., Ashrafioun, L., \& ... Conner, K. R. (2015). Comorbid depression and alcohol use disorders and prospective risk for suicide 
attempt in the year following inpatient hospitalization. Journal Of Affective Disorders, 187151-155. doi:10.1016/j.jad.2015.08.029

Bryan, C. J., Graham, E., \& Roberge, E. (2015). Living a life worth living: Spirituality and suicide risk in military personnel. Spirituality in Clinical Practice, 2(1), 74. doi: $10.1037 / \mathrm{scp} 0000056$

Bryan, A. O., Theriault, J. L., \& Bryan, C. J. (2015). Self-forgiveness, posttraumatic stress, and suicide attempts among military personnel and veterans. Traumatology, 21(1), 40-46. doi:10.1037/trm0000017

Caribé, A. C., Studart, P., Bezerra-Filho, S., Brietzke, E., Noto, M. N., Vianna-Sulzbach, M., ... \& Miranda-Scippa, Â. (2015). Is religiosity a protective factor against suicidal behavior in bipolar I outpatients?. Journal of Affective Disorders, 186, 156-161. doi:10.1016/j.jad.2015.07.024

Carpenter, T. P., Tignor, S. M., Tsang, J., \& Willett, A. (2016). Dispositional self-forgiveness, guilt- and shame-proneness, and the roles of motivational tendencies. Personality and Individual Differences, 9853-61. doi:10.1016/j.paid.2016.04.017

Centers for Disease Control and Prevention. (2013). Web-based Injury Statistics Query and Reporting System (WISQARS). Retrived from http://www.cdc.gov/injury/wisqars/fatal_injury_reports.html

Centers for Disease Control and Prevention. (2015). Understanding suicide: Fact sheet. Retrieved from https://www.cdc.gov/violenceprevention/pdf/suicide_factsheet-a.pdf

Chang, E. C., Jilani, Z., Yu, T., Fowler, E. E., Lin, J., Webb, J. R., \& Hirsch, J. K. (2015). Fundamental dimensions of personality underlying spirituality: Further evidence for the 
construct validity of the RiTE measure of spirituality. Personality and Individual Differences, 75, 175-178. doi:10.1016/j.paid.2014.11.027

Chang, E. C., Kahle, E. R., Elizabeth, A. Y., \& Hirsch, J. K. (2014). Understanding the relationship between domestic abuse and suicide behavior in adults receiving primary care: Does forgiveness matter?. Social Work, 59(4), 315-320. doi:10.1093/sw/swu028

Chen, Y. W., \& Dilsaver, S. C. (1996). Lifetime rates of suicide attempts among subjects with bipolar and unipolar disorders relative to subjects with other Axis I disorders. Biological Psychiatry, 39(10), 896-899. doi:10.1016/0006-3223(95)00295-2

Chiswick, B. R., \& Mirtcheva, D. M. (2013). Religion and child health: Religious affiliation, importance, and attendance and health status among American youth. Journal of Family and Economic Issues, 34(1), 120-140. doi:10.1007/s10834-012-9312-5

Christodoulou, C., Douzenis, A., Papadopoulos, F. C., Papadopoulou, A., Bouras, G., Gournellis, R., \& Lykouras, L. (2012). Suicide and seasonality. Acta Psychiatrica Scandinavica, 125(2), 127-146. doi:10.1111/j.1600-0447.2011.01750.x

Cohen, A. B. (2009). Many forms of culture. American Psychologist, 64(3), 194-204. doi:10.1037/a0015308

Cole-Lewis, Y. C., Gipson, P. Y., Opperman, K. J., Arango, A., \& King, C. A. (2016). Protective role of religious involvement against depression and suicidal ideation among youth with interpersonal problems. Journal of Religion and Health, 55(4), 1172-1188. doi:10.1007/s10943-016-0194-y

Connors, G. J., Tonigan, J. S., \& Miller, W. R. (1996). A measure of religious background and behavior for use in behavior change research. Psychology of Addictive Behaviors, 10(2), 90-96. doi:10.1037/0893-164X.10.2.90 
Currier, J. M., Kuhlman, S., \& Smith, P. N. (2015). Empirical and ethical considerations for addressing spirituality among veterans and other military populations at risk for suicide. Spirituality in Clinical Practice, 2(1), 68-73. doi:10.1037/scp0000057

Curtin, S. C., Warner, M., \& Hedegaard, H. (2016a). Increase in Suicide in the United States, 1999-2014. NCHS data brief, (241), 1-8.

Curtin, S. C., Warner, M., \& Hedegaard, M. D. (2016b). Suicide Rates for Females and Males by Race and Ethnicity: United States, 1999 and 2014. Retreived from Center of Disease Control and Prevention website: http://www.cdc.gov/nchs/data/hestat/suicide/rates_1999_2014.pdf

Davis, D. E., Ho, M. Y., Griffin, B. J., Bell, C., Hook, J. N., Van Tongeren, D. R., \& Westbrook, C. J. (2015). Forgiving the self and physical and mental health correlates: A metaanalytic review. Journal of Counseling Psychology, 62(2), 329-335. doi:10.1037/cou0000063

Davis, D. E., Worthington, E. J., Hook, J. N., \& Hill, P. C. (2013). Research on religion/spirituality and forgiveness: A meta-analytic review. Psychology of Religion and Spirituality, 5(4), 233-241. doi:10.1037/a0033637

de Jager Meezenbroek, E., Garssen, B., van den Berg, M., Tuytel, G., van Dierendonck, D., Visser, A., \& Schaufeli, W. B. (2012). Measuring spirituality as a universal human experience: Development of the Spiritual Attitude and Involvement List (SAIL). Journal of Psychosocial Oncology, 30(2), 141-167. doi:10.1080/07347332.2011.651258

DeLisle, M., \& Holden, R. (2009). Differentiating between depression, hopelessness, and psychache in university undergraduates. Measurement and Evaluation in Counseling and Development, 42, 46-63. doi: 10.1177/0748175609333562 
Dell'Osso, L., Massimetti, G., Conversano, C., Bertelloni, C. A., Carta, M. G., Ricca, V., \& Carmassi, C. (2014). Alterations in circadian/seasonal rhythms and vegetative functions are related to suicidality in DSM-5 PTSD. BMC Psychiatry, 14(1), 1.

Effinger, J. M., \& Stewart, D. G. (2012). Classification of co-occurring depression and substance abuse symptoms predicts suicide attempts in adolescents. Suicide and Life-Threatening Behavior, 42(4), 353-358. doi:10.1111/j.1943-278X.2012.00092.x

Ellis, A. (1962). Reason and emotion in psychotherapy. Secaucus, NJ: Lyle Stuart.

Ellison, C. G., \& Levin, J. S. (1998). The religion-health connection: Evidence, theory, and future directions. Health Education \& Behavior, 25(6), 700-720. doi:10.1177/109019819802500603

Enright, R. D. (1996). Counseling within the forgiveness triad: On forgiving, receiving, forgiveness, and self-forgiveness. Counseling and Values, 40(2), 107-126. doi:10.1002/j.2161-007X.1996.tb00844.X

Everson, S. A., Goldberg, D. E., Kaplan, G. A., Cohen, R. D., Pukkala, E., Tuomilehto, J., \& Salonen, J. T. (1996). Hopelessness and risk of mortality and incidence of myocardial infarction and cancer. Psychosomatic Medicine, 58(2), 113-121. doi:10.1097/00006842199603000-00003

Flaskerud, J. H. (2014). Suicide Culture. Issues in Mental Health Nursing, 35(5), 403-405. doi:10.3109/01612840.2013.840019

Fowler, J. C., Hilsenroth, M. J., \& Piers, C. (2001). An empirical study of seriously disturbed suicidal patients. Journal of the American Psychoanalytic Association, 49(1), 161-186. doi:10.1177/00030651010490010901 
Fox, S. A., Pitkin, K., Paul, C., Carson, S., \& Duan, N. (1998). Breast cancer screening adherence: Does church attendance matter?. Health Education \& Behavior, 25(6), 742758. doi:10.1177/109019819802500605

Forintos, D. P., Rózsa, S., Pilling, J., \& Kopp, M. (2013). Proposal for a short version of the beck hopelessness scale based on a national representative survey in Hungary. Community Mental Health Journal, 49(6), 822-830. doi:10.1007/s10597-013-9619-1

Frankl, V. E. (1985). Man's search for meaning. Boston, Massachusetts: Beacon Press.

Galante, J., Galante, I., Bekkers, M. J., \& Gallacher, J. (2014). Effect of kindness-based meditation on health and well-being: a systematic review and meta-analysis. Journal of Consulting and Clinical Psychology, 82(6), 1101. 1101-1114. doi:10.1037/a0037249

Gallup (2015). Religion. Retrieved from http://www.gallup.com/poll/1690/religion.aspx Gallup (2016). Religion. Retrieved from http://www.gallup.com/poll/1690/religion.aspx George, L. K., Larson, D. B., Koenig, H. G., \& McCullough, M. E. (2000). Spirituality and health: What we know, what we need to know. Journal of Social And Clinical Psychology, 19(1), 102-116. doi:10.1521/jscp.2000.19.1.102

Gray, J. (2006). Measuring spirituality: Conceptual and methodological considerations. Journal of Theory Construction \& Testing, 10(2), 58.

Greenberg, J., \& Arndt, J. (2012). Terror management theory. In P. M. Van Lange, A. W. Kruglanski, E. T. Higgins, P. M. Van Lange, A. W. Kruglanski, E. T. Higgins (Eds.), Handbook of theories of social psychology, Vol. 1 (pp. 398-415). Thousand Oaks, CA: Sage Publications Ltd. doi:10.4135/9781446249215.n20 
Hall, J. H., \& Fincham, F. D. (2005). Self-forgiveness: The stepchild of forgiveness research. Journal of Social And Clinical Psychology, 24(5), 621-637. doi:10.1521/jscp.2005.24.5.621

Hall, J. H., \& Fincham, F. D. (2008). The temporal course of self-forgiveness. Journal of Social and Clinical Psychology, 27(2), 174-202. doi:10.1521/jscp.2008.27.2.174

Harris, E. C., \& Barraclough, B. (1997). Suicide as an outcome for mental disorders. A metaanalysis. The British Journal of Psychiatry, 170(3), 205-228. doi:10.1192/bjp.170.3.205

Hayes, A. (2013). Introduction to mediation, moderation, and conditional process analysis: A regression-based approach. New York: Guildford Press.

Hedge, A. (2013, August). Biological Rhythms - Cornell University Ergonomics Web. Retrieved November 2, 2016, from http://ergo.human.cornell.edu/studentdownloads/DEA3250pdfs/biorhythms.pdf

Hendin, H. (1991). The psychodynamics of suicide. American Journal of Psychiatry, 148(9), $1150-1158$.

Hill, P. C., \& Hood, R. W., Jr (Eds.). (1999). Measures of religiosity. Birmingham, AL: Religious Education Press.

Hirsch, J. K., Webb, J. R., \& Jeglic, E. L. (2011). Forgiveness, depression, and suicidal behavior among a diverse sample of college students. Journal of Clinical Psychology, 67(9), 896906. doi:10.1002/jclp.20812

Hirsch, J. K., Webb, J. R., \& Jeglic, E. L. (2012). Forgiveness as a moderator of the association between anger expression and suicidal behaviour. Mental Health, Religion \& Culture, 15(3), 279-300. doi:10.1080/13674676.2011.571666 
Holden, R. R., Mehta, K., Cunningham, E. J., \& McLeod, L. D. (2001). Development and preliminary validation of a scale of psychache. Canadian Journal of Behavioural Science/Revue canadienne des sciences du comportement, 33(4), 224-232. doi:10.1037/h0087144

Horton, S. E. (2015). Religion and Health-Promoting Behaviors Among Emerging Adults. Journal of Religion and Health, 54(1), 20-34. doi:10.1007/s10943-013-9773-3

Huber, S., \& Huber, O. W. (2012). The centrality of religiosity scale (CRS). Religions, 3(3), 710724.

Johnson, K. S., Tulsky, J. A., Hays, J. C., Arnold, R. M., Olsen, M. K., Lindquist, J. H., \& Steinhauser, K. E. (2011). Which domains of spirituality are associated with anxiety and depression in patients with advanced illness?. Journal of General Internal Medicine, 26(7), 751-758. doi:10.1007/s11606-011-1656-2

Joiner, T. (2005). Why people die by suicide. Cambridge, MA: Harvard University Press.

Jokinen, J., Ouda, J., \& Nordström, P. (2010). Noradrenergic function and HPA axis dysregulation in suicidal behaviour. Psychoneuroendocrinology, 35(10), 1536-1542.

Keith, T. Z. (2015). Multiple regression and beyond: An introduction to multiple regression and structural equation modeling. 2nd ed. New York, NY, US: Routledge/Taylor \& Francis Group.

Kim, Y. K., Hwang, J. A., Lee, H. J., Yoon, H. K., Ko, Y. H., Lee, B. H., ... \& Na, K. S. (2014). Association between norepinephrine transporter gene (SLC6A2) polymorphisms and suicide in patients with major depressive disorder. Journal of Affective Disorders, 158, 127-132. doi:10.1016/j.jad.2014.01.018 
Kleiman, E. M., \& Liu, R. T. (2014). Prospective prediction of suicide in a nationally representative sample: religious service attendance as a protective factor. The British Journal of Psychiatry, 204(4), 262-266. doi:10.1192/bjp.bp.113.128900

Koenig, H. G., King, D. E., \& Carson, V. B. (2012). Handbook of religion and health (Second ed.). New York, NY: Oxford University Press.

Koenig, H. G., \& Larson, D. B. (2001). Religion and mental health: Evidence for an association. International Review of Psychiatry, 13(2), 67-78. doi:10.1080/09540260124661

Koenig, L. B., \& Vaillant, G. E. (2009). A prospective study of church attendance and health over the lifespan. Health Psychology, 28(1), 117- 124. doi:10.1037/a0012984

Kopacz, M. S. (2015). Spirituality and suicide prevention: Charting a course for research and clinical practice. Spirituality in Clinical Practice, 2(1), 79-81. doi:10.1037/scp0000062

Lester, D. (2012). Spirituality and religiosity as predictors of depression and suicidal ideation: an exploratory study. Psychological Reports, 110(1).

Lester, D., \& Bean, J. (1992). Attribution of causes to suicide. The Journal of Social Psychology, 132(5), 679-680. doi:10.1080/00224545.1992.9713907

Lin, W., Mack, D., Enright, R. D., Krahn, D., \& Baskin, T. W. (2004). Effects of Forgiveness Therapy on Anger, Mood, and Vulnerability to Substance Use Among Inpatient Substance-Dependent Clients. Journal of Consulting and Clinical Psychology, 72(6), 1114-1121. doi:10.1037/0022-006X.72.6.1114

Linardakis, M., Papadaki, A., Smpokos, E., Sarri, K., Vozikaki, M., \& Philalithis, A. (2015). Are religiosity and prayer use related with multiple behavioural risk factors for chronic diseases in European adults aged 50+ years?. Public Health, 129(5), 436-443. doi:10.1016/j.puhe.2015.02.006 
Litz, B. T., Stein, N., Delaney, E., Lebowitz, L., Nash, W. P., Silva, C., \& Maguen, S. (2009). Moral injury and moral repair in war veterans: A preliminary model and intervention strategy. Clinical Psychology Review, 29(8), 695-706. doi:10.1016/j.cpr.2009.07.003

Lomas, T., Ridge, D., Cartwright, T., \& Edginton, T. (2014). Engagement with meditation as a positive health trajectory: Divergent narratives of progress in male meditators. Psychology \& Health, 29(2), 218-236. doi:10.1080/08870446.2013.843684

Lovibond, S. H., \& Lovibond, P. F. (1993). Manual for the Depression Anxiety Stress Scales. Sydney, Australia: Psychology Foundation.

Lovibond, P. F., \& Lovibond, S. H. (1995). The structure of negative emotional states: Comparison of the Depression Anxiety Stress Scales (DASS) with the Beck Depression and Anxiety Inventories. Behaviour Research and Therapy, 33(3), 335-343. doi:10.1016/0005-7967(94)00075-U

Lyons, G. B., Deane, F. P., Caputi, P., \& Kelly, P. J. (2011). Spirituality and the treatment of substance use disorders: An exploration of forgiveness, resentment and purpose in life. Addiction Research \& Theory, 19(5), 459-469. doi:10.3109/16066359.2011.555022

Macaskill, A. (2012). Differentiating dispositional self-forgiveness from other-forgiveness: Associations with mental health and life satisfaction. Journal of Social and Clinical Psychology, 31(1), 28-50. doi:10.1521/jscp.2012.31.1.28

Maltby, J., Macaskill, A., \& Day, L. (2001). Failure to forgive self and others: A replication and extension of the relationship between forgiveness, personality, social desirability and general health. Personality and Individual Differences, 30(5), 881-885. doi:10.1016/S0191-8869(00)00080-5

Mann, J. J. (1998). The neurobiology of suicide. Nature Medicine, 4(1), 25-30. 
Masters, K. S., \& Hooker, S. A. (2013). Religiousness/spirituality, cardiovascular disease, and cancer: Cultural integration for health research and intervention. Journal of Consulting and Clinical Psychology, 81(2), 206. doi:10.1037/a0030813

Matthews, E. (1998). Choosing death: philosophical observations on suicide and euthanasia. Philosophy, Psychiatry, \& Psychology, 5(2), 107-111.

McCullough, M., \& Smith, T. (2003). Religion and health: depressive symptoms and mortality as case studies,[w:] M. Dillon (ed.), Handbook of the sociology of religion.

Miller, J. M., Hesselgrave, N., Ogden, R. T., Sullivan, G. M., Oquendo, M. A., Mann, J. J., \& Parsey, R. V. (2013). Positron emission tomography quantification of serotonin transporter in suicide attempters with major depressive disorder. Biological Psychiatry, 74(4), 287-295. doi:10.1016/j.biopsych.2013.01.024

Miller, L., Wickramaratne, P., Gameroff, M. J., Sage, M., Tenke, C. E., \& Weissman, M. M. (2012). Religiosity and major depression in adults at high risk: A ten-year prospective study. The American Journal of Psychiatry, 169(1), 89-94. doi:10.1176/appi.ajp.2011.10121823

Milner, A., Krnjacki, L., Butterworth, P., \& LaMontagne, A. D. (2016). The role of social support in protecting mental health when employed and unemployed: A longitudinal fixed-effects analysis using 12 annual waves of the HILDA cohort. Social Science \& Medicine, 15320-26. doi:10.1016/j.socscimed.2016.01.050

Monod, S., Brennan, M., Rochat, E., Martin, E., Rochat, S., \& Büla, C. J. (2011). Instruments measuring spirituality in clinical research: a systematic review. Journal of General Internal Medicine, 26(11), 1345-1357. doi:10.1007/s11606-011-1769-7 
Mouzelis, N. (2012). Modernity and the secularization debate. Sociology, 46(2), 207-223. doi:10.1177/0038038511428756

Murphy, P. E., Ciarrocchi, J. W., Piedmont, R. L., Cheston, S., Peyrot, M., \& Fitchett, G. (2000). The relation of religious belief and practices, depression, and hopelessness in persons with clinical depression. Journal of Consulting and Clinical Psychology, 68(6), 1102. doi:10.1037/0022-006X.68.6.1102

Nagra, G. S., Lin, A., \& Upthegrove, R. (2016). What bridges the gap between self-harm and suicidality? The role of forgiveness, resilience and attachment. Psychiatry Research, 241, 78-82. doi:10.1016/j.psychres.2016.04.103

Neff, K. D., Rude, S. S., \& Kirkpatrick, K. L. (2007). An examination of self-compassion in relation to positive psychological functioning and personality traits. Journal of Research in Personality, 41(4), 908-916. doi: 10.1016/j.jrp.2006.08.002

Norton, M. C., Singh, A., Skoog, I., Corcoran, C., Tschanz, J. T., Zandi, P. P., ... \& Cache County Investigators. (2008). Church attendance and new episodes of major depression in a community study of older adults: the Cache County Study. The Journals of Gerontology Series B: Psychological Sciences and Social Sciences, 63(3), P129-P137. doi:10.1093/geronb/63.3.P129

Nsamenang, S. A., Webb, J. R., Cukrowicz, K. C., \& Hirsch, J. K. (2013). Depressive symptoms and interpersonal needs as mediators of forgiveness and suicidal behavior among rural primary care patients. Journal of Affective Disorders, 149(1), 282-290. doi:10.1016/j.jad.2013.01.042

Osman, A., Bagge, C. L., Gutierrez, P. M., Konick, L. C., Kopper, B. A., \& Barrios, F. X. (2001). The Suicidal Behaviors Questionnaire--Revised (SBQ-R): Validation with 
clinical and nonclinical samples. Assessment, 8(4), 443-454.

doi:10.1177/107319110100800409

Paiva, C. E., Paiva, B. S. R., Yennurajalingam, S., \& Hui, D. (2014). The Impact of Religiosity and Individual Prayer Activities on Advanced Cancer Patients' Health: Is There Any Difference in Function of Whether or Not Receiving Palliative Anti-neoplastic Therapy?. Journal of Religion and Health, 53(6), 1717-1727. doi:10.1007/s10943-013-9770-6

Pandey, G. N. (2013). Biological basis of suicide and suicidal behavior. Bipolar Disorders, 15(5), 524-541. doi:10.1111/bdi.12089

Pargament, K. I. (1999). The psychology of religion and spirituality? Yes and no. International Journal for the Psychology of Religion, 9, 3-16. doi:10.1207/s15327582ijpr0901_2

Pargament, K. I. (2013). Searching for the sacred: Toward a nonreductionistic theory of spirituality. In K. I. Pargament, J. J. Exline, \& J. W. Jones (Eds.), APA handbook of psychology, religion, and spirituality (Vol 1): Context, theory, and research. (pp. 257273). Washington, DC: American Psychological Association.

Pargament, K. I., Mahoney, A., Exline, J. J., Jones, J. W., \& Shafranske, E. P. (2013).

Envisioning an integrative paradigm for the psychology of religion and spirituality. In K. I. Pargament, J. J. Exline, \& J. W. Jones (Eds.), APA handbook of psychology, religion, and spirituality (Vol 1): Context, theory, and research. (pp. 3-19). Washington, DC: American Psychological Association.

Park, C. L., Aldwin, C. M., Choun, S., Suresh, D. P., \& Bliss, D. (2016). Spiritual peace predicts 5-year mortality in congestive heart failure patients. Health Psychology, 35(3), 203- 210. doi:10.1037/hea0000271 
Pawlak, J., Dmitrzak-Weglarz, M., Maciukiewicz, M., Wilkosc, M., Leszczynska-Rodziewicz, A., Zaremba, D., ... \& Hauser, J. (2015). Suicidal behavior in the context of disrupted rhythmicity in bipolar disorder — Data from an association study of suicide attempts with clock genes. Psychiatry Research, 226(2), 517-520. doi:10.1016/j.psychres.2015.01.010

Piacentine, L. B. (2013). Spirituality, religiosity, depression, anxiety, and drug-use consequences during methadone maintenance therapy. Western Journal of Nursing Research, 35(6), 795-814. doi:10.1177/0193945913479452

Picone, M. (2012). Suicide and the afterlife: popular religion and the standardisation of ‘culture'in Japan. Culture, Medicine, and Psychiatry, 36(2), 391-408. doi:10.1007/s11013-012-9261-3

Piedmont, R. L. (1999). Does spirituality represent the sixth factor of personality? Spiritual transcendence and the Five-Factor Model. Journal of Personality, 67(6), 985-1013. doi:10.1111/1467-6494.00080

Piedmont, R. L., \& Wilkins, T. A. (2013). Spirituality, religiousness, and personality: Theoretical foundations and empirical applications. In K. I. Pargament, J. J. Exline, \& J. W. Jones (Eds.), APA handbook of psychology, religion, and spirituality (Vol 1): Context, theory, and research. (pp. 173-186). Washington, DC: American Psychological Association.

Pompili, M., Serafini, G., Innamorati, M., Biondi, M., Siracusano, A., Di Giannantonio, M., .. . Möller-leimkühler, A. M. (2012). Substance abuse and suicide risk among adolescents. European Archives of Psychiatry and Clinical Neuroscience, 262(6), 469-485. doi:http://dx.doi.org.iris.etsu.edu:2048/10.1007/s00406-012-0292-0

Powell, L. H., Shahabi, L., \& Thoresen, C. E. (2003). Religion and spirituality: Linkages to physical health. American Psychologist, 58(1), 36- 52. doi:10.1037/0003-066X.58.1.36 
Rasic, D., Kisely, S., \& Langille, D. B. (2011). Protective associations of importance of religion and frequency of service attendance with depression risk, suicidal behaviours and substance use in adolescents in Nova Scotia, Canada. Journal of Affective Disorders, 132(3), 389-395. doi:10.1016/j.jad.2011.03.007

Reed, G. L., \& Enright, R. D. (2006). The effects of forgiveness therapy on depression, anxiety, and posttraumatic stress for women after spousal emotional abuse. Journal of Consulting and Clinical Psychology, 74(5), 920-929. doi:10.1037/0022-006X.74.5.920

Roalfe, W. R. (1928). The psychology of suicide. The Journal Of Abnormal And Social Psychology, 23(1), 59-67. doi:10.1037/h0070377

Roff, L. L., Klemmack, D. L., Parker, M., Koenig, H. G., Sawyer-Baker, P., \& Allman, R. M. (2005). Religiosity, smoking, exercise, and obesity among southern, community-dwelling older adults. Journal of Applied Gerontology, 24(4), 337-354. doi:10.1177/0733464805278132

Ross, S. R., Hertenstein, M. J., \& Wrobel, T. A. (2007). Maladaptive correlates of the failure to forgive self and others: Further evidence for a two-component model of forgiveness. Journal of Personality Assessment, 88(2), 158-167. doi:10.1080/00223890701267985

Saarinen, P. I., Viinamäki, H., Hintikka, J., Lehtonen, J., \& Lönnqvist, J. (1999). Psychological symptoms of close relatives of suicide victims. The European Journal of Psychiatry, 13(1), 33-39.

Scherer, M., Worthington, E. L., Jr., Hook, J. N., \& Campana, K. L. (2011). Forgiveness and the bottle: Promoting self-forgiveness in individuals who abuse alcohol. Journal of Addictive Diseases, 30(4), 382-395. doi:10.1080/10550887.2011.609804 
Scourfield, J., Fincham, B., Langer, S., \& Shiner, M. (2012). Sociological autopsy: An integrated approach to the study of suicide in men. Social Science \& Medicine, 74(4), 466-473. doi:10.1016/j.socscimed.2010.01.054

Siegrist, M. (1996). Church attendance, denomination, and suicide ideology. The Journal of Social Psychology, 136(5), 559-566. doi:10.1080/00224545.1996.9714040

Shneidman, E. S. (1985). Definition of suicide. New York: Wiley.

Shneidman, E. (1993). Suicide as psychache: A clinical approach to self-destructive behavior. Lanham, MD: Rowman \& Littlefield Publishers, Inc.

Shneidman, E. S. (1996). The suicidal mind. New York: Oxford University Press.

Slater, W., Hall, T. W., \& Edwards, K. J. (2001). Measuring religion and spirituality: Where are we and where are we going?. Journal of Psychology and Theology, 29(1), 4-21.

Smith, G., \& Cooperman, A. (2015). America's changing religious landscape. Washington, DC: Pew Research Center. Retrieved from: http://www.pewforum.org/2015/05/12/americaschanging-religious-landscapel

Sorrell, J. M. (2015). Meditation for older adults: A new look at an ancient intervention for mental health. Journal of Psychosocial Nursing and Mental Health Services, 53(5), 1519. doi:10.3928/02793695-20150330-01

Stack, S. (2000). Suicide: a 15-year review of the sociological literature part II: modernization and social integration perspectives. Suicide and Life-Threatening Behavior, 30(2), 163176.

Stack, S., \& Kposowa, A. J. (2016). Culture and suicide acceptability: A cross-national, multilevel analysis. The Sociological Quarterly, 57(2), 282-303. doi:10.1111/tsq.12109 
Substance Abuse and Mental Health Services Administration. (2013). Results from the 2013 National Survey on Drug Use and Health: Mental Health Findings. Rockville, MD: U.S. Dept. of Health and Human Services, Substance Abuse and Mental Health Services Administration, Center for Behavioral Health Statistics and Quality.

Suda, A., Kawanishi, C., Kishida, I., Sato, R., Yamada, T., Nakagawa, M., ... \& Hirayasu, Y. (2009). Dopamine D2 receptor gene polymorphisms are associated with suicide attempt in the Japanese population. Neuropsychobiology, 59(2), 130-134. doi:10.1159/000213566

Tangney, J. P., Boone, A. L., \& Dearing, R. (2005). Forgiving the self: Conceptual issues and empirical findings. In E. L. Worthington Jr. (Ed.), Handbook of forgiveness (pp. 143158). New York, NY: Routledge.

Toussaint, L. L., \& Williams, D. R. (2008). National survey results for Protestant, Catholic, and nonreligious experiences of seeking forgiveness and of forgiveness of self, of others, and by God. Journal of Psychology and Christianity, 27(2), 120-130.

Toussaint, L. L., Worthington, E. L., Jr., \& Williams, D. R. (Eds.). (2015). Forgiveness and health: Scientific evidence and theories relating forgiveness to better health. New York, NY: Springer.

Troister, T., D’Agata, M. T., \& Holden, R. R. (2015). Suicide risk screening: Comparing the Beck Depression Inventory-II, Beck Hopelessness Scale, and Psychache Scale in undergraduates. Psychological Assessment, 27(4), 1500-1506. doi:10.1037/pas0000126

Troister, T., \& Holden, R. R. (2010). Comparing psychache, depression, and hopelessness in their associations with suicidality: A test of Shneidman's theory of suicide. Personality and Individual Differences, 49(7), 689-693. doi:10.1016/j.paid.2010.06.006 
Troister, T., \& Holden, R. R. (2012). A two-year prospective study of psychache and its relationship to suicidality among high-risk undergraduates. Journal of Clinical Psychology, 68(9), 1019-1027. doi:10.1002/jclp.21869

Troister, T., \& Holden, R. R. (2013). Factorial differentiation among depression, hopelessness, and psychache in statistically predicting suicidality. Measurement and Evaluation in Counseling and Development, 46(1), 50-63. doi:10.1177/0748175612451744

Turecki, G. (2014). The molecular bases of the suicidal brain. Nature Reviews Neuroscience, 15(12), 802-816. doi:10.1038/nrn3839

Uchino, B. N. (2006). Social support and health: a review of physiological processes potentially underlying links to disease outcomes. Journal of Behavioral Medicine, 29(4), 377-387.

Underwood, L. G., \& Teresi, J. A. (2002). The daily spiritual experience scale: Development, theoretical description, reliability, exploratory factor analysis, and preliminary construct validity using health-related data. Annals of Behavioral Medicine, 24(1), 22-33. doi:10.1207/S15324796ABM2401_04

Upchurch, D. M., Dye, C. E., Chyu, L., Gold, E. B., \& Greendale, G. A. (2010). Demographic, behavioral, and health correlates of complementary and alternative medicine and prayer use among midlife women: 2002. Journal of Women's Health, 19(1), 23-30.

Walmsley, B. D., \& McCormack, L. (2016). Synthesis of meaning: Negative and positive change in family members following the adversity of dementia. Journal of Humanistic Psychology, 56(2), 122-143. doi:10.1177/0022167814557547

Webb, J. R. (2007). Spiritual factors and adjustment in medical rehabilitation: Understanding forgiveness as a means of coping. In A. E. DellOrto, \& P. W. Power (Eds.), The psychological and social impact of illness and disability, 5th ed, (pp. 455-471). New 
York: Springer Publishing Company. (Reprinted from: Journal of Applied Rehabilitation Counseling, 34(3), 16-24, 2003).

Webb, J. R., Bumgarner, D., Conway-Williams, E., \& Dangel, T. J. (2016). A consensus definition of self-forgiveness: Implications for assessment and treatment. Manuscript submitted for publication.

Webb, J. R., Hirsch, J. K., \& Toussaint, L. (2015). Forgiveness as a positive psychotherapy for addiction and suicide: Theory, research, and practice. Spirituality in Clinical Practice, 2(1), 48-60. doi:10.1037/scp0000054

Webb, J. R., \& Jeter, B. R. (2015). Forgiveness and problematic substance use. In L. L. Toussaint, E. L. Worthington, Jr., D. R. Williams (Eds.), Forgiveness and health: Scientific evidence and theories relating forgiveness to better health (pp. 139-154). New York, NY, US: Springer Science + Business Media. doi:10.1007/978-94-017-9993-5_10

Webb, J. R., Phillips, T. D., Bumgarner, D., \& Conway-Williams, E. (2013). Forgiveness, mindfulness, and health. Mindfulness, 4(3), 235-245. doi:10.1007/s12671-012-0119-0

Webb, J. R., Robinson, E. A., Brewer, K. J., \& Zucker, R. A. (2006). Forgiveness and alcohol problems among people entering substance abuse treatment. Journal of Addictive Diseases, 25(3), 55-67. doi:10.1300/J069v25n03_08

Webb, J. R., Toussaint, L., \& Conway-Williams, E. (2012). Forgiveness and health: Psychospiritual integration and the promotion of better healthcare. Journal of Health Care Chaplaincy, 18(1-2), 57-73. doi:10.1080/08854726.2012.667317

Webb, J. R., Toussaint, L., \& Dula, C. S. (2014). Ritualistic, theistic, and existential spirituality: Initial psychometric qualities of the RiTE measure of spirituality. Journal of Religion and Health, 53(4), 972-985. doi:10.1007/s10943-013-9697-y 
Wohl, M. A., DeShea, L., \& Wahkinney, R. L. (2008). Looking within: Measuring state selfforgiveness and its relationship to psychological well-being. Canadian Journal of Behavioural Science / Revue Canadienne Des Sciences Du Comportement, 40(1), 1-10. doi:10.1037/0008-400x.40.1.1.1

Wollschleger, J., \& Beach, L. (2011). A cucumber for a cow: A theoretical exploration of the causes and consequences of religious hypocrisy. Rationality and Society, 23(2), 155-174. doi:10.1177/1043463111404673

Woodyatt, L., Worthington, E. L., Jr., Wenzel, M., \& Griffin, B. J. (Eds.). (2016). Handbook of the psychology of self-forgiveness. New York, NY: Springer (under contract).

World Health Organization (2014). Preventing suicide: A global imperative. Retrieved from:http://apps.who.int/iris/bitstream/10665/131056/8/9789241564878_eng.pdf?ua=1

Wright, L. S., Frost, C. J., \& Wisecarver, S. J. (1993). Church attendance, meaningfulness of religion, and depressive symptomatology among adolescents. Journal of Youth and Adolescence, 22(5), 559-568. doi:10.1007/BF01537716

Wray, M., Colen, C., \& Pescosolido, B. (2011). The sociology of suicide. Annual Review of Sociology, 37, 505-528. doi:10.1146/annurev-soc-081309-150058

Xu, J., Kochanek, K., Murphy, S., \& Arias, E. (2014). Mortality in the United States, 2012. Retrieved from: http://www.cdc.gov/nchs/data/databriefs/db168.pdf Young, J. (2002). Morals, suicide, and psychiatry: A view from Japan. Bioethics, 16(5), 412-424. Zhang, J. (2016). From psychological strain to disconnectedness. Crisis, 37(3), 169-175. doi:10.1027/0227-5910/a000420 
Zinnbauer, B. J., Pargament, K. I., \& Scott, A. B. (1999). The emerging meanings of religiousness and spirituality: Problems and prospects. Journal of Personality, 67(6), 889-919. doi:10.1111/1467-6494.00077

\section{APPENDICES}

\section{Appendix A}

\section{Demographic Information}

Please indicate the following:

1. Which system are you using to access/complete this study? Mechanical Turk SONA

2. What is your unique ID Number, based on the system you are using to access/complete this study:

3. Gender: male female transgender

4. Age (Date of Birth): Day (dd): ___ Month $(\mathrm{mm}): \_\_$Year (yyyy):

5.Education Level:

Less than High School Vocational Bachelors Masters Doctoral

High School Graduate/GED School/Degree Degree Degree Degree

Graduate

other (e.g., 1 year of college; Bachelors, plus unfinished Masters work; etc.):

$\begin{array}{lllllllll}\text { 6.Current Year in College: } & 1 & 2 & 3 & 4 & 5 & 6 & 7+ & \text { Not applicable }\end{array}$

7.Race/Ethnicity: 


$\begin{array}{llll}\begin{array}{l}\text { American Indian } \\ \text { Pacific Islander }\end{array} & \text { Asian } & \text { Black/African American } & \text { Native Hawaiian/Other } \\ \text { White } & \text { Hispanic } & \text { Latino/a } & \text { other: }\end{array}$

8. Self-Identified sexual orientation:

Heterosexual Bisexual Homosexual other, please specify:

9. Marital Status: $\quad$ single (never married) married separated divorced

Committed relationship cohabitating widowed

other:

10. How many children do you have:

11. Gross yearly income (family):

$\begin{array}{llll}\text { under } 10,000 & 20,001-40,000 & 60,001-80,000 & \\ 10,001-20,000 & 40,001-60,000 & 80,001-100,000 & \text { over } 100,000\end{array}$

12. Height:

feet inches

13. Weight: pounds

14. Religious Affiliation:

\begin{tabular}{|c|c|c|c|}
\hline Atheist & Catholic & Jewish & Buddhist \\
\hline Agnostic & Baptist & Muslim & Hindu \\
\hline
\end{tabular}

15. If you live in the United States, What is your 5-digit ZIP CODE:

16. If you live in the United States, What City and State do you live in? City _ State

17. Are you a Veteran? Yes No 
18. In terms of your political views, where would you place yourself on the following scale (indicate/choose a number):

\author{
1 Extremely Liberal \\ 2 Very Liberal \\ 3 Liberal \\ 4 Somewhat Liberal \\ 5 Moderate \\ 6 Somewhat Conservative \\ 7 Conservative \\ 8 Very Conservative \\ 9 Extremely Conservative \\ 10 Decline to Answer
}

19. Are you a United States Citizen? Yes No

20. If a United States Citizen, In terms of your political views, do you consider yourself:

Not Applicable Democrat Republican Independent Other:

21 If a United States Citizen, Are you registered to vote?

Not Applicable No, and I never have been No, but I have been in the past

Yes, but recently for the first time Yes, and have been consistently

22. Do you use tobacco (e.g., cigarettes, cigars, smokeless tobacco)? Yes No

23. Do you have a chronic illness(es)? Yes No Please list: 
24. Are you the parent of a child/person with special needs:

25. If so, are you the: father step-father mother
Yes step-mother
No

Not Applicable

26. Number of Children with a disability:

27. Disability (or disabilities) that your child(ren) has/have: 
Appendix B

The RiTE Spirituality Measure

\section{PLEASE READ THE FOLLOWING DEFINITIONS:}

This survey is for use with different cultures, so keep in mind that deity/deities can have several meanings, including supremeness of one God or Goddess, multiple gods/goddesses, a higher power, a divine quality in nature and/or the universe, etc. As such, please think of the term deity/deities as it applies to you.

For example, if you are a: Buddhist, read deity or deities as "Buddha"

Christian or Jew, read deity or deities as "God", "Jehovah," or "Yahweh"

Hindu, read deity or deities as "Brahma" "Shiva", "Vishnu," "Ram," etc.

Muslim, read deity or deities as "Allah"

Spiritual, non-specific, read deity or deities as "Nature," "Higher Power," etc.

Wiccan, read deity or deities as "The Goddess," "Horned God," etc.

READ EACH ITEM AND MARK THE LEVEL OF AGREEMENT THAT COMES CLOSEST TO HOW YOU THINK, FEEL, OR BELIEVE.

1. A deity or deities was/were responsible for the creation of the universe.
A. Strongly Disagree
B. Disagree
C. Neutral/No Opinion
D. Agree
E. Strongly Agree

2. The world was created by a deity or deities.
A. Strongly Disagree
B. Disagree
C. Neutral/No Opinion
D. Agree
E. Strongly Agree

3. I believe in a deity or deities.
A. Strongly Disagree
B. Disagree
C. Neutral/No Opinion
D. Agree
E. Strongly Agree

4. I believe in a deity or deities who know/s me. 

A. Strongly Disagree
B. Disagree
C. Neutral/No Opinion
D. Agree
E. Strongly Agree

5. A deity or deities is/are at some time going to judge the rightness or wrongness of the actions of individuals.
A. Strongly Disagree
B. Disagree
C. Neutral/No Opinion
D. Agree
E. Strongly Agree

6. I feel connected to a deity or deities.
A. Strongly Disagree
B. Disagree
C. Neutral/No Opinion
D. Agree
E. Strongly Agree

7. I feel belief in a deity or deities is very important.
A. Strongly Disagree
B. Disagree
C. Neutral/No Opinion
D. Agree
E. Strongly Agree

8. I believe in a deity or deities who has/have a purpose/plan for my life.
A. Strongly Disagree
B. Disagree
C. Neutral/No Opinion
D. Agree
E. Strongly Agree

9. I believe in a deity or deities who has/have power to control world events.
A. Strongly Disagree
B. Disagree
C. Neutral/No Opinion
D. Agree
E. Strongly Agree

10. It is important to acknowledge the existence or reality of a deity or deities.
A. Strongly Disagree
B. Disagree
C. Neutral/No Opinion
D. Agree
E. Strongly Agree

11. I regularly perform traditional spiritual practices.
A. Strongly Disagree
B. Disagree
C. Neutral/No Opinion
D. Agree
E. Strongly Agree

12. I observe or follow the rules of a formal belief system.
A. Strongly Disagree
B. Disagree
C. Neutral/No Opinion
D. Agree
E. Strongly Agree

13. I regularly attend organized worship services.
A. Strongly Disagree
B. Disagree
C. Neutral/No Opinion
D. Agree
E. Strongly Agree

14. I feel faith-related rituals and/or practices are very important.
A. Strongly Disagree
B. Disagree
C. Neutral/No Opinion
D. Agree
E. Strongly Agree 
15. I set aside time to contemplate issues related to religious or spiritual teachings.
A. Strongly Disagree
B. Disagree
C. Neutral/No Opinion
D. Agree
E. Strongly Agree

16. I regularly meditate as I have been taught in my faith.
A. Strongly Disagree
B. Disagree
C. Neutral/No Opinion
D. Agree
E. Strongly Agree

17. I feel good after I attend organized worship services.
A. Strongly Disagree
B. Disagree
C. Neutral/No Opinion
D. Agree
E. Strongly Agree

18. Observing or following traditions is a very important part of spirituality or faith.
A. Strongly Disagree
B. Disagree
C. Neutral/No Opinion
D. Agree
E. Strongly Agree

19. It is important to tell others about one's own spiritual path in order to try and convince them of the correct path.
A. Strongly Disagree
B. Disagree
C. Neutral/No Opinion
D. Agree
E. Strongly Agree

20. I would not be good in the judgment of a deity or deities if I did not practice my faith as prescribed.
A. Strongly Disagree
B. Disagree
C. Neutral/No Opinion
D. Agree
E. Strongly Agree

21. I feel that helping others is very important.
A. Strongly Disagree
B. Disagree
C. Neutral/No Opinion
D. Agree
E. Strongly Agree

22. Helping other people is very important.
A. Strongly Disagree
B. Disagree
C. Neutral/No Opinion
D. Agree
E. Strongly Agree

23. I feel that understanding oneself is very important.
A. Strongly Disagree
B. Disagree
C. Neutral/No Opinion
D. Agree
E. Strongly Agree

24. I believe that finding meaning and purpose in life is very important.
A. Strongly Disagree
B. Disagree
C. Neutral/No Opinion
D. Agree
E. Strongly Agree 
25. I feel that taking care of nature is very important.
A. Strongly Disagree
B. Disagree
C. Neutral/No Opinion
D. Agree
E. Strongly Agree

26. Human life is a beautiful thing.
A. Strongly Disagree
B. Disagree
C. Neutral/No Opinion
D. Agree
E. Strongly Agree

27. There is a right way to treat other people.
A. Strongly Disagree
B. Disagree
C. Neutral/No Opinion
D. Agree
E. Strongly Agree

28. There is a wrong way to treat other people.
A. Strongly Disagree
B. Disagree
C. Neutral/No Opinion
D. Agree
E. Strongly Agree

29. It is the responsibility of each person to find their purpose in life.
A. Strongly Disagree
B. Disagree
C. Neutral/No Opinion
D. Agree
E. Strongly Agree

30. I see life as a journey toward fulfillment.
A. Strongly Disagree
B. Disagree
C. Neutral/No Opinion
D. Agree
E. Strongly Agree 


\section{Appendix C}

The Heartland Forgiveness Measure

\section{Directions:}

In the course of our lives negative things may occur because of our own actions, the actions of others, or circumstances beyond our control. For some time after these events, we may have negative thoughts or feelings about ourselves, others, or the situation. Think about how you typically respond to such negative events. For the following items indicate the number (from the 7-point scale below) that best describes how you typically respond to the type of negative situation described. There are no right or wrong answers. Please be as open as possible in your answers.

\begin{tabular}{|cccccc|}
\hline 1 & 2 & 3 & 5 & 6 & 7 \\
$\begin{array}{c}\text { Almost Always } \\
\text { False of Me }\end{array}$ & $\begin{array}{c}\text { More Often } \\
\text { False of Me }\end{array}$ & $\begin{array}{c}\text { More Often } \\
\text { True of Me }\end{array}$ & $\begin{array}{c}\text { Almost Always } \\
\text { True of Me }\end{array}$ \\
\hline Question & & & &
\end{tabular}

1. Although I feel bad at first when I mess up, over time I can give myself some slack.

2. I hold grudges against myself for negative things l've done.

3. Learning from bad things that l've done helps me get over them.

4. It is really hard for me to accept myself once l've messed up.

5. With time I am understanding of myself for mistakes I've made.

6. I don't stop criticizing myself for negative things l've felt, thought, said, or done.

7. I continue to punish a person who has done something that I think is wrong.

8. With time I am understanding of others for the mistakes they've made.

9. I continue to be hard on others who have hurt me. 
10. Although others have hurt me in the past, I have eventually been able to see them as good people. ...

11. If others mistreat me, I continue to think badly of them.

12. When someone disappoints me, I can eventually move past it.

13. When things go wrong for reasons that can't be controlled, I get stuck in negative thoughts about it. ...

14. With time I can be understanding of bad circumstances in my life.

15. If I am disappointed by uncontrollable circumstances in my life, I continue to think negatively about them.

16. I eventually make peace with bad situations in my life.

17. It's really hard for me to accept negative situations that aren't anybody's fault.

18. Eventually I let go of negative thoughts about bad circumstances that are beyond anyone's control. 


\section{Appendix D}

\section{Suicidal Behaviors Questionnaire- Revised}

Instructions: Please indicate the statement or phrase that best applies to you.

1. Have you ever thought about or attempted to kill yourself? (Circle only one):

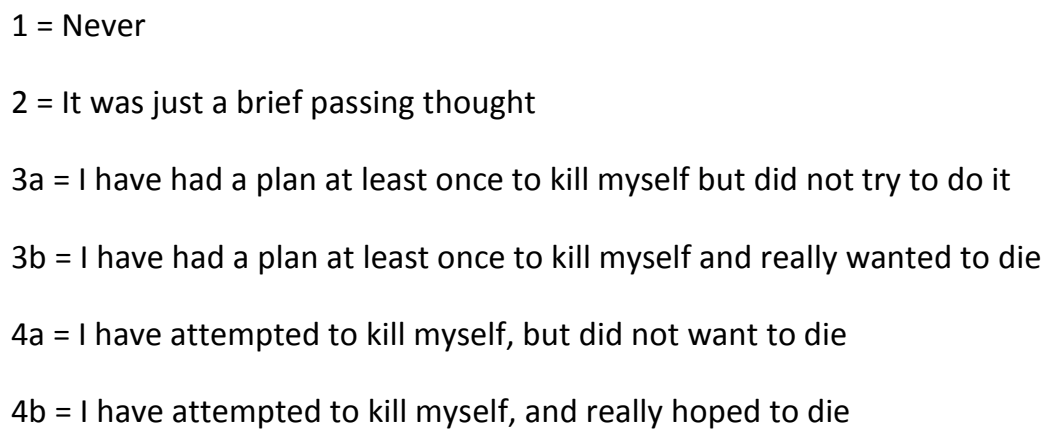

2. How often have you thought about killing yourself in the past year? (Circle only one):

$$
\begin{aligned}
& 1=\text { Never } \\
& 2=\text { Rarely ( } 1 \text { time) } \\
& 3=\text { Sometimes ( } 2 \text { times) } \\
& 4=\text { Often ( } 3-4 \text { times) } \\
& 5=\text { Very Often ( } 5 \text { or more times) }
\end{aligned}
$$

3. Have you ever told someone that you were going to commit suicide, or that you might do it? (Circle only one):

$$
\begin{aligned}
& 1=\text { No } \\
& 2 a=\text { Yes, at one time, but did not really want to die } \\
& 2 b=\text { Yes, at one time, and really wanted to do it } \\
& 3 a=\text { Yes, more than once, but did not want to do it } \\
& 3 b=\text { Yes, more than once, and really wanted to do it }
\end{aligned}
$$

4. How likely is it that you will attempt suicide someday? (circle only one):

$$
\begin{aligned}
& 0=\text { Never } \\
& 1=\text { No chance at all }
\end{aligned}
$$


$2=$ Rather Unlikely

$3=$ Unlikely

4 = Likely

$5=$ Rather Likely

$6=$ Very Likely 


\section{Appendix E}

The Psychache Scale

The following statements refer to your psychological pain, NOT your physical pain. By selecting the appropriate response, please indicate how frequently each of the following occur.

\begin{tabular}{|c|c|c|c|c|c|}
\hline \multirow[t]{2}{*}{2 = Sometimes } & $3=$ Often & 4 = Very Often & \multicolumn{3}{|c|}{$5=$ Always } \\
\hline & Never & Sometimes & Often & Very Often & Always \\
\hline 1. I feel psychological pain. & 1 & 2 & 3 & 4 & 5 \\
\hline 2. I seem to ache inside. & 1 & 2 & 3 & 4 & 5 \\
\hline 3. My psychological pain seems & 1 & 2 & 3 & 4 & 5 \\
\hline
\end{tabular}

worse than any physical pain.

4. My pain makes me $\quad 1 \quad 2 \quad 3 \quad 4 \quad 5$

want to scream.

5. My pain makes my

1

2

3

4

5

life seem dark.

\begin{tabular}{lccccc} 
6. I can't understand why I suffer. & 1 & 2 & 3 & 4 & 5 \\
7. Psychologically, I feel terrible. & 1 & 2 & 3 & 4 & 5 \\
8. I hurt because I feel empty. & 1 & 2 & 3 & 4 & 5 \\
9. My soul aches. & 1 & 2 & 3 & 4 & 5 \\
\hline
\end{tabular}


Please continue this inventory using the following scale:

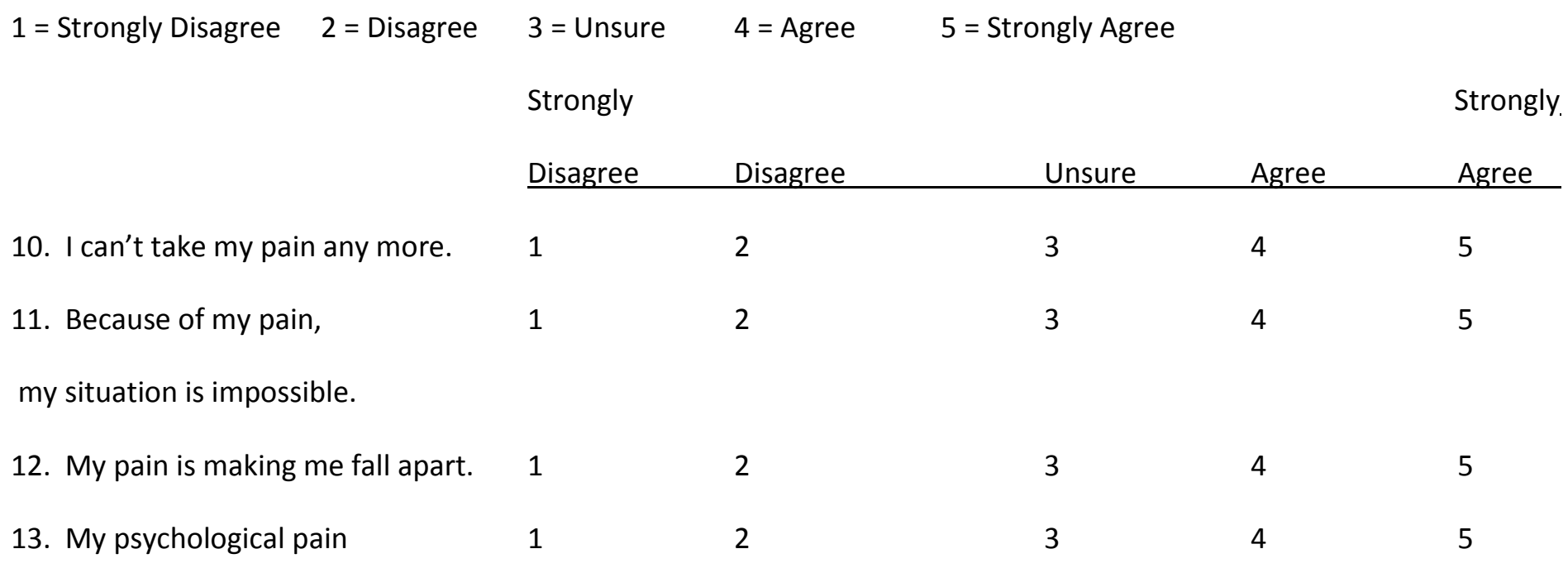

affects everything I do. 
VITA

\section{BENJAMIN HALL}

Education:

M.A. Psychology, Concentration in Clinical Psychology, East

Tennessee State University, 2017

B.A. Psychology, Harding University, Searcy, Arkansas, 2013

Professional Experience: Graduate Assistant, East Tennessee State University, Johnson City, Tennessee, 2015-2017

Student Clinician, ETSU Behavioral Health and Wellness Clinic, East Tennessee State University, Johnson City, Tennessee 2017-present

Presentations:

Hall, B. B., Dangel, T. J., \& Webb, J. R., (2017, August; Accepted). Spirituality and Suicidal Behavior: the Role of Varying Dimensions of Forgiveness. Poster to be presented at the 125th Annual Conference of the APA, Division 36: Washington, DC.

Webb, J. R., Hall, B. B., \& Dangel, T. J., (2017, August; in review). Multidimensional spirituality, multidimensional forgiveness, and psychological distress among college student problematic drinkers. Poster presentation at the 125th Annual Conference of the APA, Division 36: Washington, DC.

Hall, B. B., Pugh, K. C., Dangel, T. J., Hirsch, J. K., \& Webb, J.R., (2017, April; In Review). Forgiveness and Psycache: The Protective Role of Forgiveness against Psychological Distress. Symposium Presentation at the Annual Mid-Year Conference of the Division 36 of APA: Chattanooga, TN.

Dangel, T. J., Hall, B. B., \& Webb, J. R., (2017, April; In Review). Forgiveness and Suicidal Behavior: The Mediating Role of Psychological Distress. Symposium Presentation at the 
Annual Mid-Year Conference of the Division 36 of APA: Chattanooga, TN.

Pugh, K. C., Hall, B. B., Hirsch, J. K., \& Webb, J.R., (2017, April; In Review). Dimensions of Spirituality and Suicidal Behavior: Examining Serial Linkages of Self-Compassion and Psychache. Poster presented at the 2017 Annual MidYear Conference of the Division 36 of APA: Chattanooga, TN.

Hall, B. B., Reyes, A., \& Webb, J. R., (2016, April). Psychache and Suicidal: Does Spirituality Matter?. Poster presented at the 2016 Middle Tennessee Psychological Association annual conference: Murfreesboro, TN.

Hall, B. B., Dangel, T. J., Reyes, A. M., \& Webb, J. R., (2016, March). Exploring Associations between Attachment to God, Self-Esteem, and Life Satisfaction among College Students. Poster presented at the 2016 Annual Mid-Year Conference of the Division 36 of APA: Brooklyn, NY.

Hall, B. (2013, April). Effects of Scenario Gender and Scenario Ethnicity on Perceptions of Success. Poster presented at Alpha Chi Honor Society National Convention, Nashville, TN.

Hall, B. (2013, April). Effects of Scenario Gender and Scenario Ethnicity on Perceptions of Success. Poster presented at Arkansas Symposium for Psychology Students, Conway, AR.

Honors:

Who's Who Among College Students, Harding University, Searcy, Arkansas, 2013 